\title{
WestVirginiaUniversity
}

THE RESEARCH REPOSITORY @ WVU

Graduate Theses, Dissertations, and Problem Reports

2002

\section{Variables affecting compliance of pigeons}

Adam H. Doughty

West Virginia University

Follow this and additional works at: https://researchrepository.wvu.edu/etd

\section{Recommended Citation}

Doughty, Adam H., "Variables affecting compliance of pigeons" (2002). Graduate Theses, Dissertations, and Problem Reports. 1667.

https://researchrepository.wvu.edu/etd/1667

This Dissertation is protected by copyright and/or related rights. It has been brought to you by the The Research Repository @ WVU with permission from the rights-holder(s). You are free to use this Dissertation in any way that is permitted by the copyright and related rights legislation that applies to your use. For other uses you must obtain permission from the rights-holder(s) directly, unless additional rights are indicated by a Creative Commons license in the record and/ or on the work itself. This Dissertation has been accepted for inclusion in WVU Graduate Theses, Dissertations, and Problem Reports collection by an authorized administrator of The Research Repository @ WVU.

For more information, please contact researchrepository@mail.wvu.edu. 
Variables affecting compliance of pigeons

Adam H. Doughty

Dissertation submitted to the Eberly College of Arts and Sciences at West Virginia University

in partial fulfillment of the requirements for the degree of

Doctor of Philosophy in Psychology

\author{
Kennon A. Lattal, Ph.D., Committee Chair \\ Michael Perone, Ph.D. \\ Cynthia M. Anderson, Ph.D. \\ Julie Vargas, Ph.D. \\ Barry Edelstein, Ph.D.
}

Department of Psychology

Morgantown, West Virginia

2002

Keywords: compliance, animal model, high-probability request procedure, behavioral momentum, foot in the door, door in the face 


\author{
Abstract \\ Variables affecting compliance of pigeons \\ Adam H. Doughty
}

Pigeons served in experiments modeling compliance techniques studied by applied behavior analysts and social psychologists. A discrete-trial procedure operated in each experiment. In baseline, each trial consisted of a single key color, and in test conditions, each trial consisted of a sequence of key colors. Across experiments, there were either two or three trial types in baseline. When there were two, one color was correlated with a low fixed ratio (FR) on half the trials, and on the other trials a second color was correlated with another schedule that differed across experiments. Food was delivered on most of the low-FR trials, and on only a portion of the trials of the latter type. When there were three trial types, two were as just described, and a third color, correlated with extinction, occurred on the other third of the trials. In test conditions, a sequence of key colors, each with its correlated consequences, preceded the key color correlated with food on only a portion of its trials. Relative to baseline, responding to this latter key increased under a high FR when each key color in the preceding sequence was correlated with either a low FR (one experiment) or extinction (another experiment). The functional equivalence between the effects of the two sequences then was assessed by comparing, across conditions, different combinations of the two stimuli in a single sequence (e.g., low FR-extinction-low FR versus extinction-low FR-extinction). The results, however, were inconclusive. Effects of sequences comprised of only the low FR then were studied across experiments in which the high FR was replaced by either a variable-interval (VI) or differential-reinforcement-of-low-rate (DRL) schedule. Response rates changed little under the VI and increased under the DRL. A behavioral conceptualization of compliance, the value of animal models of compliance, the study of compliance as a link between basic and applied behavior analysis, and between behavior analysis and social psychology, as well as different accounts of compliance change, all are discussed. 
Acknowledgements

I thank the following individuals who contributed to this dissertation: Andy Lattal, Mike Perone, Dave Schaal, Cindy Anderson, Julie Vargas, Barry Edelstein, Stephanie da Silva, Megan Meginley, Chris Podlesnik, Jen King, and Shannon Haag.

Andy was my committee chair on this dissertation, my advisor in graduate school, and the chair of my undergraduate honor's thesis. In all, I have spent the last 5 and 1/2 years in his lab. I cannot describe in this limited space how much Andy has impacted my life both personally and professionally; however, I write the following: Andy is a wonderful person! This description is meant to encompass all of our interactions from weekly meetings in his office to lab meetings, from lunches to BSing in the lab, from our times in London (particularly at Skinner's Arms) to the classes he taught, etc. It was an absolute pleasure to have interacted with Andy and for this interaction I will be forever changed... I mean... I will be changed forever! Thank you, Andy!

Mike, Dave, Cindy, Julie, and Barry all served on my dissertation committee. Each made valuable comments and has altered this research and its description in important ways. Stephanie, Megan, and I have had many discussions concerning this research, as well as about almost every other topic. I have learned much from them and am grateful to have shared the Lattal Lab with them! Chris and Jen helped me conduct, respectively, the three experiments of this dissertation and Pigeon Model 1. I thank each of them for their valuable aid. Finally, I thank Shannon for many, many things... in brief, she provided an environment in which I enjoyed myself! I hope I did the same for her. 


\section{List of Figures}

Figure 1. Percent reinforcers obtained for each pigeon in the final six sessions of each

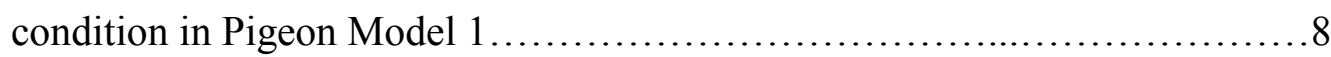

Figure 2. Percent reinforcers obtained for each pigeon in the final six sessions of each condition in Pigeon Model 2 ........................................... 11

Figure 3. Percent reinforcers obtained for each pigeon in the final six sessions of each condition in Experiment 1

Figure 4. Pecks per second for each pigeon in the final six sessions of each condition in

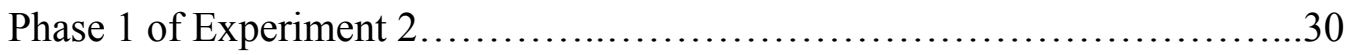

Figure 5. Pecks per second for each pigeon in the final six sessions of each condition in

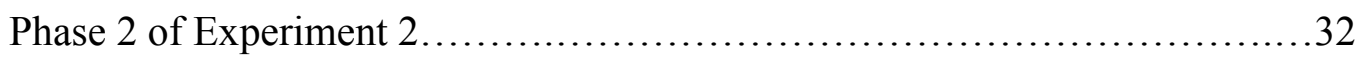

Figure 6. Percent reinforcers obtained under the VI schedules for each pigeon in the final six sessions of each condition in Phases 1 (left graphs) and 2 (right graphs) of Experiment 2 ....

Figure 7. Percent reinforcers obtained for each pigeon in the final six sessions of each condition in Experiment 3

Figure 8. Mean latency (in seconds) for each pigeon across the final six sessions of each condition in Experiment 3

Figure 9. Percent reinforcers obtained (top graph) and mean latency in seconds (bottom graph) for Pigeon 247 in the final six sessions of each of four conditions 


\section{List of Tables}

Page

Table 1. Order of conditions and number of sessions in each condition for each pigeon in

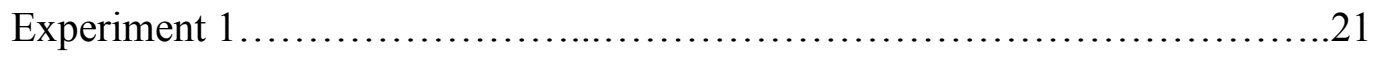

Table 2. Order of conditions and number of sessions in each condition for each pigeon in

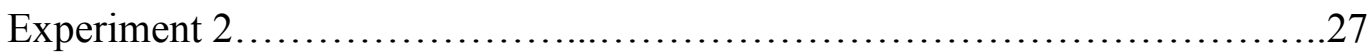

Table 3. Order of conditions and number of sessions in each condition for each pigeon in

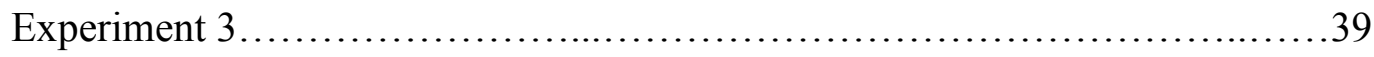


$\begin{array}{ll}\text { Page } & \end{array}$

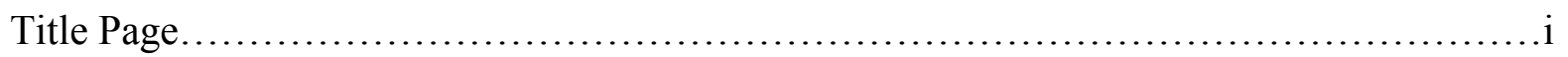

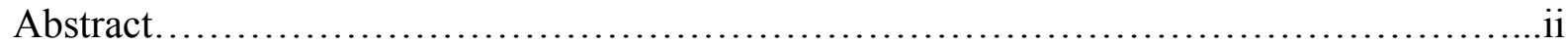

Acknowledgements.........................................................

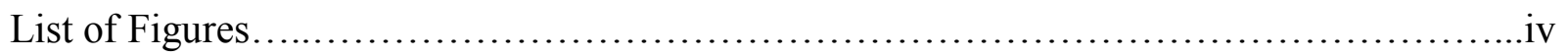

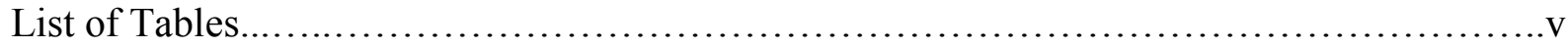

Chapter 1 - Overview...................................................... 1

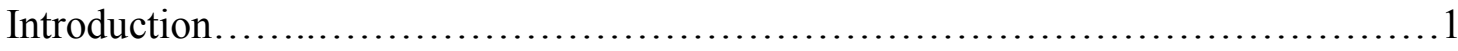

Literature Review.........................................................2

Social psychology and compliance.....................................2

Applied behavior analysis and compliance............................4

Two experiments modeling compliance techniques with pigeons.............6

Compliance and other behavioral processes: Theoretical accounts...........12

Statement of the Problem.................................................. 16

Chapter 2 - Experimental Methods and Results...................................17

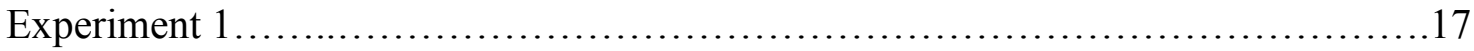

Method................................................................. 18

Subjects................................................18

Apparatus................................................... 18

Procedure.................................................18

Results......................................................20

Discussion........................................................ 24

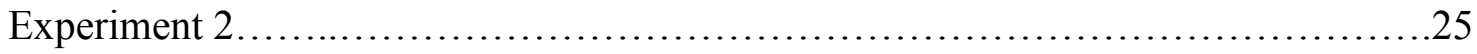

Method......................................................26

Subjects....................................................26

Apparatus................................................26

Procedure..................................................26

Results...................................................... 28

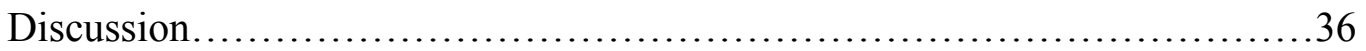




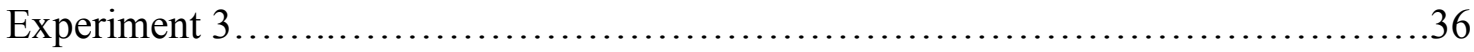

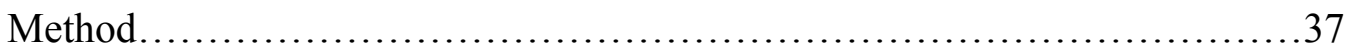

Subjects................................................. 37

Apparatus.....................................................37

Procedure..................................................... 37

Results......................................................40

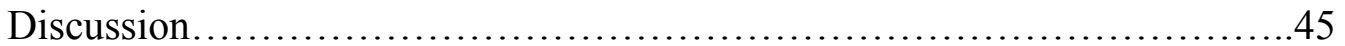

Chapter 3 - Conclusions....................................................46

General Discussion...................................................46

A behavioral conceptualization of compliance............................49

The value of animal models of compliance...............................49

The study of compliance as a link between basic and applied behavior analysis, and between behavior analysis and social psychology.......51

Different accounts of compliance change.................................55

Concerns surrounding animal compliance.............................57

Future compliance research........................................58

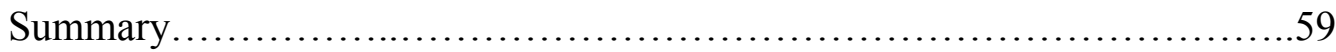

References....................................................60 
Chapter 1 - Overview

\section{Introduction}

Although Skinner (1938) began the experimental analysis of behavior by studying lever pressing of rats, he repeatedly asserted that a main purpose of such a field was its potential to impact human behavior (e.g., Skinner, 1953, 1957, 1971, 1974). Despite these claims by Skinner and others (e.g., Hake, 1982; Mace, 1994), there is a continuing separation between basic and applied behavior analysis, as well as a division between behavior analysis and other areas of psychology concerned almost exclusively with human behavior (e.g., social psychology; cf. Guerin, 1992; Lana, 1994). One direction behavior analysts have taken to integrate basic research with its application is the development of animal models (e.g., Lattal \& Doepke, 2001; cf. Mace, 1994). Despite the unifying function these models serve, animal models of compliance have yet to be developed, though they have been discussed by applied researchers (Mace, Mauro, Boyajian, \& Eckert, 1997).

Compliance has been the subject of considerable study in both social psychology and applied behavior analysis. Thus, animal models of compliance may provide a link between basic and applied behavior analysis and between behavior analysis and social psychology. Compliance typically refers to the correspondence between a response of one individual and a request of that response from another individual, given that the response is controlled, in part, by the request, and often that the two events occur within a specified period of time. Studying compliance follows partly from the fact that the responses requested by others often "benefit" the individual receiving the request, but that the responses are not forthcoming without intervention. A patient complying with a request from a doctor to self-medicate, for example, is more likely to recover from illness than one who does not comply, but often such a request occasions noncompliance. Compliance has received attention in applied behavior analysis due to its particularly low prevalence with individual with developmental disabilities (e.g., Mace et al., 1988).

It has been claimed that the study of compliance answers the question, "How can a person be induced to do something he would rather not do?" (Freedman \& Fraser, 1966, p. 237). Freedman and Fraser noted two approaches to generating compliance. First, compliance can be increased by altering its consequences. These authors, however, discussed ethical and practical limitations that often prevent the manipulation of such consequences. In part for these reasons, 
social psychologists have assessed many of the antecedent conditions controlling compliance (see Cialdini, 1984, 1995 for reviews).

A behavioral interpretation of the question posed by Freedman and Fraser (1966) is, "How can a low-probability response be made into a high-probability response?" Applied behavior analysts have examined both antecedent and consequent conditions influencing compliance. And although the behavioral principles controlling compliance have not been articulated fully, the high-probability (high-p) request procedure (Mace et al., 1988) has received empirical and theoretical attention in applied behavior analysis. This procedure has increased compliance in a variety of situations, and further analyses of its efficacy are an integral step in articulating fully the environment-behavior relations subsumed by the term compliance (cf. Mace et al., 1997).

This paper offers a behavioral conceptualization of compliance by presenting several experiments examining some of the conditions affecting compliance. Research on compliance from social psychology and applied behavior analysis first is reviewed. Two experiments from our laboratory designed as animal models of compliance then are summarized, and a framework to account for the behavior change observed therein is offered. Finally, three experiments were conducted to test the predictions of this framework as well as to better understand the behavioral variables controlling compliance.

\section{Literature Review \\ Social psychology and compliance}

Two compliance techniques studied by social psychologists are foot in the door and door in the face. Foot in the door is when compliance with a "large" request is higher when that request follows compliance with a "small" request, relative to when only the large request occurs (cf. Freedman \& Fraser, 1966). Freedman and Fraser asked each of several housewives to allow an investigator into her home to collect data on household products. For each participant in one group, a request to respond to a questionnaire about household products preceded this request for consumer data, and each participant completed the survey. Participants in a second group did not receive the request to complete the survey. A significantly higher percentage of individuals in the group receiving both requests complied with the large one, and this percentage also was higher than another group designed to control for familiarity between the requester and the participants. 
Foot in the door also influences money donation (Pliner, Hart, Kohl, \& Saari, 1974). Participants divided into two groups were requested to donate to a cancer society, however, each participant of one group first was asked to wear a pin supporting that society, whereas the others were not. Significantly more individuals in the group receiving both requests donated money.

Foot in the door has been described primarily in terms of self-perception theory (e.g., Freedman \& Fraser, 1966). According to that theory (cf. Bem, 1970), behavior is controlled largely by societal pressures forcing individuals to act in ways consistent with their self-image. For foot in the door, individuals perceive themselves as helpful after complying with the initial request, and they then comply with the second request to preserve this image.

The operation of door in the face, a second compliance technique studied in social psychology, is opposite to that of foot in the door. With door in the face, compliance is higher with a "moderate" request when that request follows noncompliance with a large request, relative to when the large request is omitted. Cialdini et al. (1975) initially asked participants in one group to volunteer two hours per week for two years at a juvenile detention center, a request that occasioned noncompliance from each participant. For each participant of a second group, this initial request to volunteer was omitted. Participants from both groups then were asked to supervise a group of juvenile delinquents on a single, two-hour field trip, and significantly more individuals who received both requests complied with the latter one.

There are at least two interpretations of door in the face. One, called reciprocal concessions (e.g., Cialdini et al., 1975), relies on the reciprocity norm (cf. Cialdini, 1984), which dictates that individuals aid those individuals who have aided them. For door in the face, higher compliance with the moderate request is due to the perceived reduction between the two requests such that the reduction functions as a compromise. Consequently, compliance with the moderate request itself is a compromise. A second interpretation is based on perceptual contrast, which governs how behavior is affected by events occurring sequentially. Placing one's hand in $80^{\circ}$ water, for example, produces different responses after its removal from either $100^{\circ}$ or $60^{\circ}$ water (Cialdini, 1984). For door in the face, higher compliance with the moderate request is due to the perception that that request is less severe following a severe request than when presented alone. 
Applied behavior analysis and compliance

Three compliance techniques studied by applied behavior analysts are the high-p procedure, task interspersal, and response-independent stimulus delivery. The high-p procedure has been studied mainly using individuals with developmental disabilities. In a typical study of the high-p procedure (e.g., Mace et al., 1988), a list of high- and low-p requests initially is constructed by interviewing individuals who interact with the participant regularly. A high-p request is correlated with a high (100\%) level of compliance, and a low-p request is correlated with a lower level. A "high-5", for example, may be correlated with a high-p request and taking out the garbage with a low-p request. In each session of a subsequent baseline condition, a single high- or low-p request is presented to the participant every $60 \mathrm{~s}$. Compliance with each request typically is reinforced by praise, whereas noncompliance receives no programmed consequence and is defined as the absence of the requested response within a fixed period of time (e.g., $10 \mathrm{~s}$ ). The high-p procedure then is implemented after responding stabilizes.

With the implementation of the high-p procedure, three or four high-p requests are presented after the 60-s interval, and compliance with each is reinforced. The time between the end of one reinforcer and the next request typically is brief (e.g., $2 \mathrm{~s}$ ) and fixed. A low-p request then is presented shortly after (e.g., 2 s) the final reinforcer of the high-p sequence and its correlated consequences remain unchanged from baseline. Compliance with low-p requests consequently increases to approximately $100 \%$, and this result has occurred with a toddler with developmental disabilities (McComas, Wacker, \& Cooper, 1998), children with developmental disabilities (e.g., Davis \& Reichle, 1996), children who are typically developing (e.g., Rortvedt \& Miltenberger, 1994), and adults with developmental disabilities (e.g., Mace et al., 1988).

The efficacy of the high-p procedure has been described primarily by behavioral momentum theory (e.g., Mace, 1996, 2000; Mace et al., 1988; Nevin, 1996). This theory was derived from observations in physics wherein the momentum of an object is the product of its velocity and mass (Nevin, 1992; Nevin, Mandell, \& Atak, 1983; see Nevin \& Grace, 2000, for a review). Behavioral momentum, therefore, is the product of the rate of a response (velocity) and the relative resistance to disruption of that response (mass). Thus, if two responses occur at similar rates but one is more resistant to a rate-reducing operation (see below), then this latter one is said to have greater momentum. In basic behavior analysis, momentum theory has been 
applied to data arising from a research design wherein, in general, pecking of pigeons is maintained in separate components of a multiple schedule according to different reinforcer parameters (e.g., different reinforcer rates). Extinction, prefeeding (i.e., satiation), or responseindependent food delivery (occurring between the components) then is arranged, and relative resistance is calculated by comparing the rate of each response in disruption to its own baseline rate. Responding that remains closer to its own baseline rate is characterized as more resistant to change. Higher reinforcer rates, larger reinforcer magnitudes, shorter reinforcer delays (signaled or unsignaled), and higher quality reinforcers all generate relatively greater resistance to change (e.g., Bell, 1999; Grace, Schwendiman, \& Nevin, 1998; Mace et al., 1997; Nevin, 1974). For the high-p procedure, the high-p sequence generates momentum for the response class of compliance such that it subsequently persists when presented with disruption (i.e., a low-p request).

Another interpretation of the effects of the high-p procedure (Houlihan \& Brandon, 1996; McGill, 1999; Smith \& Iwata, 1997) relies on establishing operations (Michael, 1982, 1993, 2000). Establishing operations are manipulations that enhance the reinforcing efficacy of stimuli. Food deprivation, for example, is an establishing operation as food generally controls the responding of an organism better when that organism is more food deprived. For the high-p procedure, attention is made momentarily more effective in the control of compliance as the rate of attention increases at least threefold with the execution of the high-p sequence.

Both task interspersal and response-independent stimulus delivery increase compliance. Task interspersal (e.g., Neef, Iwata, \& Page, 1980) has been used mainly with children who are typically developing and are exposed to novel math and English items. With task interspersal, already-learned items are placed in the context of to-be-learned items (i.e., the same worksheet), and acquisition, performance, and retention of these novel items are enhanced, relative to when the already-learned items are omitted. Kennedy, Itkonen, and Lindquist (1995) compared compliance change as a function of response-independent stimulus delivery and the high-p procedure. The operation of the high-p procedure was as described previously, and in another condition, three or four response-independent "social comments" preceded each low-p request. Relative to baseline, compliance was increased to similar levels by the high-p procedure and response-independent stimulus delivery (but see Mace et al., 1988).

A common interpretation has been applied to the effects of both task interspersal and 
response-independent stimulus delivery. With each, reinforcer rate increases relative to baseline, dependent on responding with the former and independently of responding with the latter, and this greater rate enhances reinforcer efficacy for low-p compliance. This interpretation resembles the account of the high-p procedure based on establishing operations noted above. Two experiments modeling compliance techniques with pigeons

Two experiments recently conducted in our laboratory were designed to model with pigeons the compliance techniques reviewed above. This research is presented in detail as it provided the impetus for the experiments reported below. In each experiment, a discrete-trial procedure operated. In each session of each baseline condition in the first experiment (hereafter, Pigeon Model 1), there were 60 trials and each was preceded by a 60 -s intertrial interval (ITI). The key light and houselight were dark in the ITI, after which they were turned on. On 30 trials, the key was white and on the other 30 trials it was blue. The order of the trials was quasirandom. The key remained on for $5 \mathrm{~s}$ or until a fixed ratio (FR) was completed. If the FR was not completed in $5 \mathrm{~s}$, then the key light and houselight were darkened and, $3 \mathrm{~s}$ later, the ITI began. If the FR was completed, the key light and houselight were darkened immediately after its completion and food was available for $3 \mathrm{~s}$, after which the ITI restarted. Relatively low and high FR values were correlated with the white and blue keys, respectively, such that a relatively high and low percentage of the trials ended in food (Figure 1, Condition BL). The FR values were different for each pigeon and remained constant throughout the experiment.

In a second condition (RDF), each session was comprised of 12 trials. On six of the trials, three white-key presentations followed a 60 -s ITI, and on the other six trials there were four such presentations. Food was delivered for completion of each FR, and the time between the end of one food delivery and the next key-light onset was $2 \mathrm{~s}$. A blue-key presentation followed $2 \mathrm{~s}$ after the end of the final food delivery of the sequence, and the consequences correlated with the high FR remained unchanged from baseline. In this condition, the percentage of high-FR trials ending in food increased, subsequently decreased when baseline was reinstated, and increased when the second condition returned. In a third condition (RDF/RIF), six of the 12 trials were as just described. On the other six trials, the high FR was preceded by three (three trials) or four (three trials) response-independent food deliveries, each separated by $2 \mathrm{~s}$. The percentage of high-FR trials ending in food increased in this condition following each sequence. This result also 
Next Page

Figure 1. Percent reinforcers obtained for each pigeon in the final six sessions of each condition in Pigeon Model 1. Triangles show data from the low FR schedule. Solid circles show data from the high FR schedule in baseline conditions and following a sequence of food deliveries for responding under the low FR schedule. Empty circles show data from the high FR schedule following a sequence of response-independent food deliveries. BL refers to baseline, and RDF and RIF refer, respectively, to when the high FR schedule was preceded by a sequence of response-dependent food deliveries provided for completing the low FR schedule or responseindependent food deliveries. 
Fig. 1

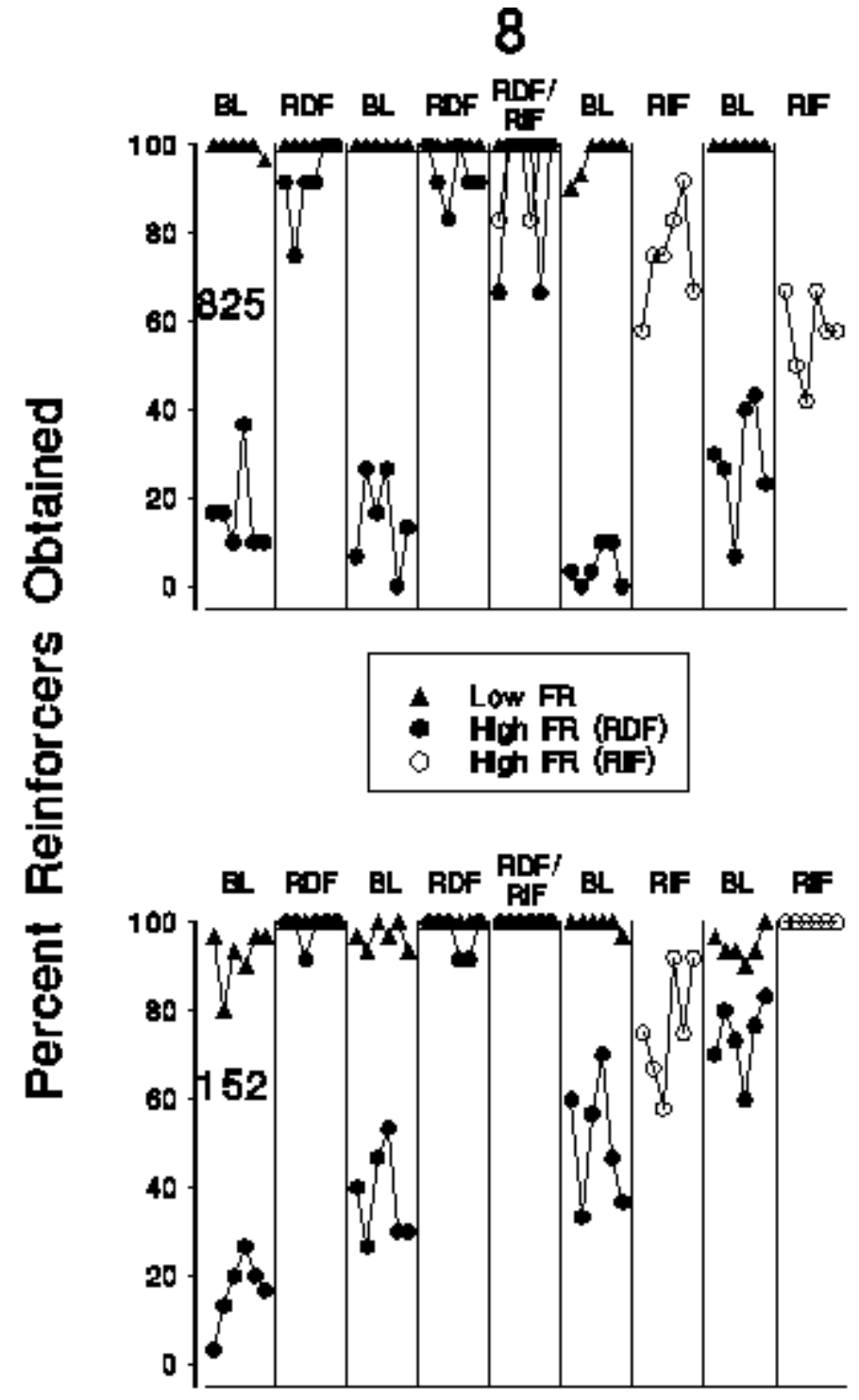

Final Six Sessions 
occurred in another condition wherein the high FR was preceded only by three (six trials) or four (six trials) response-independent food deliveries (Condition RIF) and was replicated thereafter.

In the second experiment (hereafter, Pigeon Model 2), each baseline session consisted of 60 trials presented quasirandomly, and each trial followed a 60-s ITI. Forty trials were as in baseline of Pigeon Model 1: on 20 trials, a white key correlated with a low FR occurred, and on another 20 trials a blue key with a high FR occurred. On the other 20 trials, a red key was presented for $5 \mathrm{~s}$, after which food never occurred (i.e., extinction). Red-key pecking was near zero after only a few sessions and remained thus so throughout the experiment, whereas the percentage of white- and blue-key trials ending in food was comparable to that obtained in the first experiment (Figure 2, BL).

In a second condition (Extseq), each session was comprised of 12 trials. On six of the trials, three red-key presentations followed a 60-s ITI, and on the other six trials there were four such presentations. The time between the end of one red-key presentation and the next one was 2 s. A blue-key presentation was $2 \mathrm{~s}$ after the termination of the final red-key presentation, and the consequences correlated with the high FR remained unchanged from baseline. The percentage of high-FR trials ending in food increased in this condition, decreased when baseline returned, and increased when the second condition was reinstated. In another condition (Extseq/Low FR), six of the 12 trials were as just described, and on the other six trials, only the white key was presented and food was delivered following the completion of its correlated FR. The percentage of high-FR trials ending in food across three exposures to this condition was high and this percentage generally was lower in each intervening baseline condition.

The claim is that the compliance techniques reported using humans and reviewed above were modeled using pigeons in the two aforementioned experiments. In Pigeon Model 1, the high-p procedure, foot in the door, and task interspersal were modeled in Conditions RDF and $\mathrm{RDF} / \mathrm{RIF}$, and response-independent stimulus delivery was modeled in Conditions RDF/RIF and RIF. In each of these procedures, there are two stimuli. One is correlated with a high rate of reinforcement (high-p request in the high-p procedure, small request in foot in the door, alreadylearned items in task interspersal, social comments in response-independent stimulus delivery, and a key light correlated with a low FR). 
Next Page

Figure 2. Percent reinforcers obtained for each pigeon in the final six sessions of each condition in Pigeon Model 2. Triangles show data from the low FR schedule. Circles show data from the high FR schedule. Boxes show data from the extinction (Ext) schedule. BL refers to baseline, Extseq refers to when the high FR schedule was preceded by a sequence of extinction-key presentations, and low FR refers to when the low FR was presented alone on half the trials. 
Fig. 2

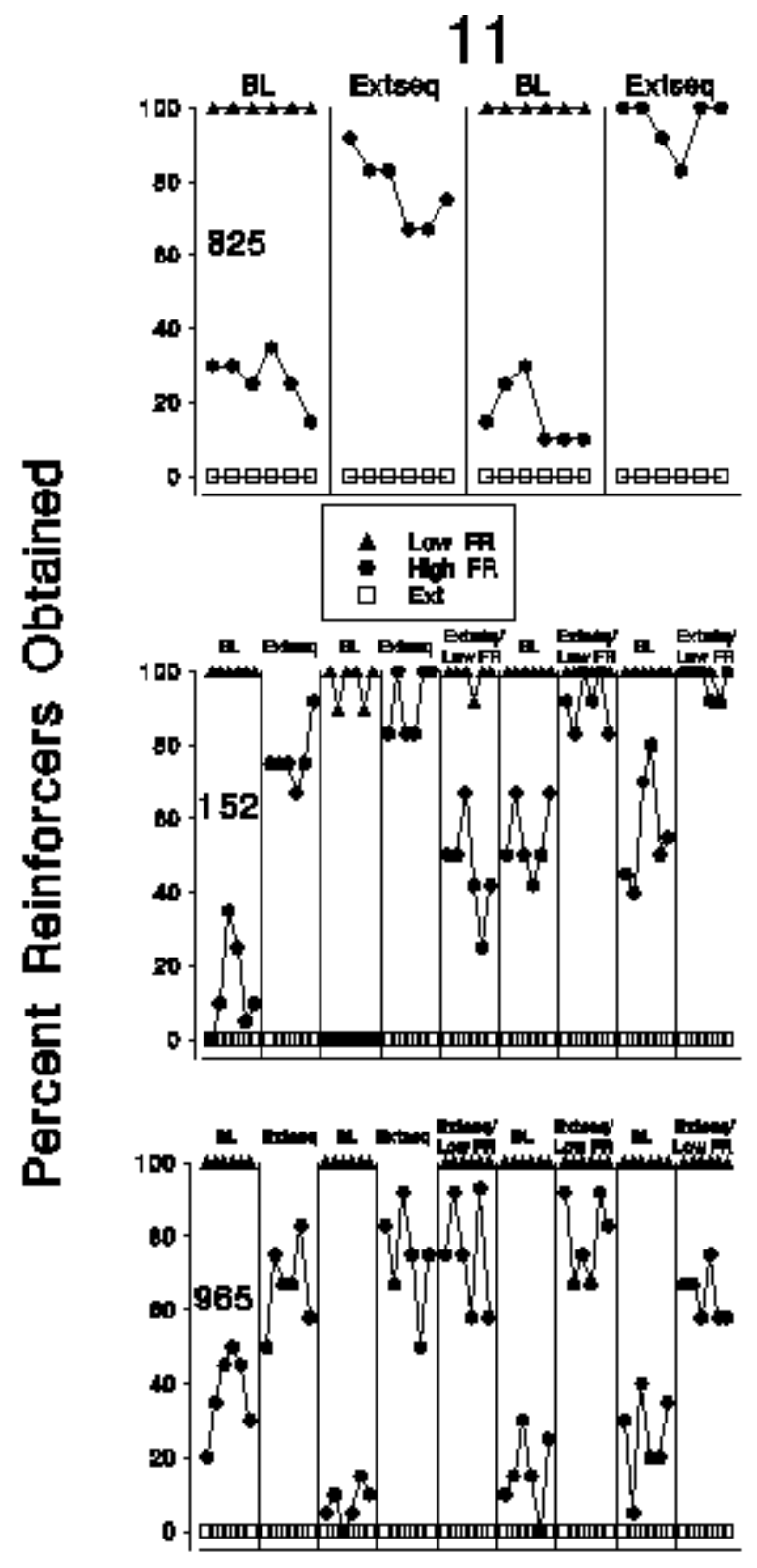

Final Six Sessions 
The other stimulus is correlated with a relatively lower reinforcement rate (low-p request in the high-p procedure and response-independent stimulus delivery, large request in foot in the door, to-be-learned items in task interspersal, and a key light correlated with a high FR). In each procedure, this latter stimulus better occasions responding when it is preceded by the former stimulus and its correlated consequences. Door in the face was modeled in Pigeon Model 2. There are, at least, two stimulus presentations in each procedure. One is correlated with nonreinforcement (large request of door in the face and a key light correlated with extinction), and the other with a relatively higher reinforcement rate (moderate request of door in the face and a key light correlated with a high FR). This latter stimulus better occasions responding when it is preceded by the former one.

Pigeon Models 1 and 2 allow for the study of compliance techniques (1) with individual subjects, (2) that are repeatedly exposed to experimental conditions, (3) revealing effects large enough to not require statistical analyses for their demonstration. These three features typically are absent in social-psychological research, and the second often is absent in applied-behavioranalytic work. Given that animal models allow for greater control over, and often the isolation of variables that may not be studied with humans, further research utilizing such models may be useful in investigating compliant behavior.

\section{Compliance and other behavioral processes: Theoretical accounts}

Research on incentive contrast (see Flaherty, 1996 for a review) and Amsel's (e.g., 1994) frustration theory relate to Pigeon Models 1 and 2. In a typical study of incentive contrast, there are four groups of rats (e.g., Crespi, 1942, as cited in Flaherty, 1996). For each rat in one group, a large reward is at the end of a runway, and for each rat in a second group a small reward is present. Each rat in a third group first is exposed to the small reward before being switched to the large one, and each rat in a fourth group first is exposed to the large reward before being switched to the small one. The group first receiving the small reward runs faster when switched to the large one than does the group that always received the large one. And the group that first received the large reward runs slower when switched to the small one than does the group that always received the small one. The former finding is successive positive contrast and the latter is successive negative contrast. Both findings are general in that they also occur when consummatory responding (i.e., licking) is studied, as opposed to running. Successive positive 
contrast relates to Amsel's frustration theory. Amsel and Roussel (1952), for example, reported that rats ran faster on an $\mathrm{S}+$ trial preceded by an $\mathrm{S}$ - trial than on an $\mathrm{S}+$ trial preceded by another $\mathrm{S}+$ trial. According to frustration theory, this increase is due to the frustrative effects of nonreward. Thus, with successive positive contrast and Pigeon Model 2, a stimulus occasions more responding when it is preceded by a less-valued stimulus (i.e., one correlated with a lower reinforcement rate or a smaller reinforcer magnitude) than when that less-valued stimulus is omitted. The results of Pigeon Model 1, however, are inconsistent with successive negative contrast as the transition from a higher-valued stimulus to a lower-valued stimulus should occasion less responding, not more.

Behavioral contrast (see Williams, 1983, 2002 for reviews) is related to incentive contrast despite different methods used to study the two (cf. Flaherty, 1996; Williams, 1997). These differences include within- versus between-subject designs, free-operant versus discrete-trial procedures, discrete versus continuous responses, and lengthy versus brief periods of training. With behavioral contrast, when a multiple variable-interval (VI) 60-s VI 60-s schedule is changed to a multiple VI 60-s extinction schedule, response rates increase under the unchanged VI 60-s schedule (i.e., positive behavioral contrast). Alternatively, if a VI 30-s schedule replaces one of the VI 60-s schedules, then responding decreases under the unchanged VI 60-s schedule (i.e., negative behavioral contrast). These response-rate changes are most robust in the initial transition from one component to the next (e.g., Malone, 1976) and consequently have been subsumed by the term local behavioral contrast. Anticipatory, or following-schedule, contrast (e.g., Williams, 1981) is a large source of contrast but is not discussed in detail here. Local positive contrast is similar to successive positive contrast and, therefore, is relevant to Pigeon Model 2. As above, however, results from Pigeon Model 1 are inconsistent with the literature on behavioral contrast. That is, the transition from a stimulus correlated with a relatively high reinforcement rate to one correlated with a relatively lower reinforcement rate ought to occasion less responding, not more.

Thus, the results of the high-p procedure and Pigeon Model 1 are inconsistent with findings on incentive and behavioral contrast. An alternative account of the results is in terms of behavioral momentum theory. This application of behavioral momentum theory, however, also has been questioned (e.g., Houlihan \& Brandon, 1996) due to the many differences between the 
high-p procedure and the typical resistance-to-change study. First, with the high-p procedure it is unclear what constitutes the alternative (multiple-schedule) component. Second, and related, it is uncertain to what compliance should be compared to when determining relative resistance to change. Third, "typical" resistance-to-change findings only are obtained in basic behavior analysis when the disrupter is applied to two different responses such that the contingencies maintaining those responses remain intact (cf. Doughty \& Lattal, in press). With the high-p procedure, however, a change in the contingency occurs with the disrupter. In sum, these procedural differences lead to a conceptual difficulty in applying momentum theory to the effects of the high-p procedure: with the latter procedure, momentum is used in an absolute sense and thus is no longer the product of response rate (velocity) and relative resistance to change (mass).

The preceding discussion invites an alternative description of the efficacy of the high-p procedure, as well as the other compliance techniques listed above. Data and theory generated by Killeen and his colleagues (Killeen, 1979, 1982, 1998; Killeen \& Bizo, 1998; Killeen, Hanson, \& Osborne, 1978; see Killeen, 1994, for a review) may provide such a description, and Killeen's framework is considered, in part, because it is similar, in some respects, to both an establishingoperations account of the high-p procedure and behavioral momentum (Killeen, 2000; Nevin, 1994). In Killeen's system, there are three reinforcement principles. The first (activation) is that each delivery of an incentive (e.g., food to a food-deprived animal) activates some period of arousal, or activity. The second (constraint) is that responses compete with one another such that one may prevent the occurrence of others. The third (coupling) is that responses "in memory" when an incentive occurs are more likely to recur, at the expense of other responses. Coupling, therefore, represents an interpretation of how the delay-of-reinforcement gradient is obtained. The first and third principles are most relevant to this discussion and thus are described in detail.

Support for the principle of activation was provided by measuring the activity (i.e., movement) of pigeons as a function of response-independent food delivery (Killeen, 1979; Killeen et al., 1978). Activity was greatest immediately after food and decreased exponentially thereafter. In addition, the greater the rate of food delivery, the greater the amount of activity. Thus, it was claimed that arousal, indexed in part through activity, was a positive function of reinforcer rate (see also Killeen, 1994, 1998). Support for the principle of coupling is found, for example, in comparisons of response rates under variable-ratio (VR) and VI schedules, in which 
higher response rates reliably occur under the former. According to coupling, this difference in response rate is the result of more target responses (e.g., key pecks) being in memory when food occurs under a VR than a VI schedule. Under a VI schedule, responses other than the target response normally are temporally proximal with food and, thus, are in memory when food is delivered. These other responses consequently are strengthened at the expense of the target response, and this situation is less likely under a VR schedule. In short, according to Killeen, incentives arouse responding and environmental stimuli then dictate the form of that responding, based on the conditioning history of the organism.

Killeen's (1994) framework accounts for the results of Pigeon Model 1. That is, the increase in responding under the high FR, as a function of the preceding food-delivery sequence, is consistent with the notion that that sequence incites activity, and that this activity subsequently takes the form of key pecking due to the presentation of the blue key with its correlated FR schedule. More precisely, this activity is greater than in baseline when only the ITI precedes the high FR and the overall rate of reinforcement is lower.

But, does the above framework describe the results of Pigeon Model 2? That is, ought a sequence of stimuli each correlated with extinction also activate responding, relative to when only an ITI precedes that schedule? As mentioned already, for Killeen (1994), activation is a positive function of reinforcer rate such that this framework does not apply to the results of the second pigeon model. Nonetheless, a single, response-activation interpretation may describe the results from both models. That is, in that stimuli correlated with extinction result in both aggression (e.g., Azrin, Hutchinson, \& Hake, 1966) and escape (e.g., Dinsmoor, Lee, \& Brown, 1986), it has been asserted that these stimuli, in fact, do generate activity (cf. Amsel, 1994). And in a more detailed explication of activation, Killeen (1998) discussed data relevant to the present issues. Warmup refers to the fact that it often takes subjects many minutes, and shock deliveries, to begin to avoid shocks as they do normally, that is, as they did in previous sessions (e.g., Hineline, 1972; Hoffman, Fleshler, \& Chorny, 1961). Warm-up occurs even after many sessions of exposure to the avoidance schedule and has been attributed, by some investigators (cf. Killeen, 1998), to an elevation of arousal in the early parts of a session as shocks accrue. Thus, it may be that the behavior change observed in Pigeon Model 2 also is due to enhanced, extinctioninduced activity. 
To summarize, the results of Pigeon Model 1 are interpretable in terms of Killeen's (1994) reinforcement principles, whereas the results of Pigeon Model 2 are consistent with research and theory on (incentive and behavioral) contrast (Flaherty, 1996; Williams, 1983, 2002). In addition, a single interpretation, resembling Killeen's framework but with an additional claim (cf. Amsel, 1994), may describe the results of each model. That is, a sequence of food deliveries and a sequence of extinction-key stimuli both may increase arousal or activity, relative to when the sequences are omitted. The form that activity takes then depends on the reinforcement conditions in effect and the organism's behavioral history. Under the high FR schedule of the two pigeon models, therefore, the increased activity generated by the preceding sequence resulted in greater key pecking as each reinforcer arranged previously under that schedule was preceded by multiple key pecks (i.e., coupling). This interpretation has at least two advantages over the accounts discussed above. First, as mentioned, it describes the data from both models. Second, several testable and easily specified predictions follow from this interpretation, for example, that the effects of a sequence of food deliveries or extinction-key presentations should be similar under the same conditions, and that those effects depend on the reinforcement schedule in effect thereafter.

\section{Statement of the Problem}

Animal models of compliance may provide a link between basic and applied behavior analysis, and between behavior analysis and social psychology. An animal model of the high-p procedure in particular may allow investigators to uncover the processes responsible for the efficacy of that procedure (cf. Mace et al., 1997). Animal models of compliance also may offer insights into the development of novel compliance techniques, and provide new methods for study in the experimental analysis of behavior. Finally, behavior analysts reject accounts of behavior change based upon processes occurring in other universes of discourse (e.g., accounts based on feelings), of the sort social psychologists often employ when describing compliance (e.g., self-image preservation). Thus, animal models of compliance may generate a more precise description of the behavioral variables controlling compliant behavior, as well as provide a more complete account of the environment-behavior relations subsumed by the term compliance.

Recent research from our laboratory illustrates how compliance may be studied with pigeons. A discrete-trial procedure operated in each of two experiments such that a key light was 
presented (a request), an FR was or was not completed in $5 \mathrm{~s}$ (compliance or noncompliance), and food was or was not delivered (reinforcement or nonreinforcement of compliance). By manipulating the FR correlated with distinct key colors, different compliant responses were created each with its own probability of occurrence. The effects of procedures designed to model compliance techniques then were investigated. In one experiment (Pigeon Model 1), compliance with a high FR was increased when preceded by either a sequence of key lights, each correlated with food delivery following the completion of a low FR, or a sequence of response-independent food deliveries, relative to when the sequences were omitted. In a second experiment (Pigeon Model 2), compliance with a high FR was increased when preceded by a sequence of key lights each correlated with extinction, relative to when the sequence was omitted. It is asserted that aspects of Pigeon Model 1 model the high-p procedure (Mace et al., 1988), task interspersal (Neef et al., 1980), response-independent stimulus delivery (Kennedy et al., 1995), and foot in the door (Freedman \& Fraser, 1966), whereas aspects of Pigeon Model 2 model door in the face (Cialdini et al., 1975).

To interpret the results of each pigeon model using a single framework, it is suggested that a sequence of food deliveries and a sequence of extinction-key presentations both enhanced arousal or activity, relative to when they were omitted (cf. Amsel, 1994; Killeen, 1994). In addition, the reinforcement conditions in effect following such sequences then determine the form of that activity. It also is contended that this interpretation has several advantages relative to other accounts of compliance change (e.g., behavioral momentum). Three experiments, therefore, were conducted to test some predictions of this proposed, response-activation interpretation, as well as to better understand the behavioral variables affecting compliance. If the proposed interpretation accounts for the results of these experiments, then compliance will be discussed as a label given to a specific set of environment-behavior relations that may be understood by terms already utilized in the experimental analysis of behavior.

Chapter 2 - Experimental Methods and Results

\section{Experiment 1}

The findings of Pigeon Model 2 are interpretable in terms of contrast or by a modified description based on Killeen's (1994) reinforcement principles. The purpose of the first experiment, therefore, was to test a prediction that follows from the latter interpretation. If two 
sequences of stimuli, one correlated with multiple food deliveries and the other with multiple extinction-key presentations, both influence responding under a high FR in the same way, then sequences consisting of any combination of these two events should affect responding similarly. On the other hand, according to a contrast account, different combinations of the two events ought to affect responding differently, for example, a sequence consisting of an FR 1, an extinction presentation, and another extinction presentation should increase responding more than an extinction-FR 1-FR 1 sequence as the former is correlated with a relatively lower reinforcement rate. Thus, Experiment 1 was conducted to study the functional equivalence of the effects of stimulus sequences consisting of different combinations of food deliveries and extinction-key presentations.

\section{Method}

\section{Subjects}

Three White Carneau pigeons were maintained at $75 \%, 80 \%$, or $85 \%$ of their free-feeding body weights. Pigeons 681 and 884 were experimentally naïve and Pigeon 956 had an experimental history. Each was housed individually with water and health grit continuously available in the home cage, and each was given supplemental feeding, if necessary, to maintain its target weight. Lights were on in the home colony from 7 am to $7 \mathrm{pm}$.

\section{Apparatus}

An operant conditioning chamber with internal dimensions of $32.5 \mathrm{~cm}$ high by $30 \mathrm{~cm}$ wide by $30 \mathrm{~cm}$ long was used. Four response keys (4- $\mathrm{cm}$ diameter) were located on the front wall, but only the right one was used, which could be transilluminated different colors. A houselight located on the lower left corner of the front wall occasionally provided general illumination. Reinforcer availability consisted of mixed grain delivered in a food hopper located behind a food aperture located directly below the right key. The aperture only was illuminated during food delivery. Programming and data recording were controlled by a computer in an adjacent room using MED-PCC software (MED Associates, Inc. \& Tatham, 1991). Extraneous noise was arranged in the experimental room to mask background events.

\section{Procedure}

Two autoshaping (Brown \& Jenkins, 1968) sessions followed habituation and magazine training. For autoshaping, after a variable 90 -s ITI, in which only the houselight was on, the key 
was transilluminated one of three colors. The order of presentation of the colors in each session was quasirandom such that each color (red, white, and green) occurred 20 times and twice in each of the ten 6-trial blocks. The key remained on for $6 \mathrm{~s}$ or until a peck occurred to it. After either event, the key light and houselight were darkened and the hopper was raised for $3 \mathrm{~s}$. This 3-s duration was in effect in all subsequent conditions and experiments, except where noted.

In the next training condition, as well as in the experiment proper, a fixed 60-s ITI was in effect wherein the key light and houselight were dark. Each session consisted of 60 trials such that one of the three key colors was presented after the ITI, along with the houselight. Each color occurred 20 times and twice in each of the ten 6-trial blocks. The order of the colors in each block was random. In the presence of each color, an FR 1 was in effect such that a single key peck was followed by food so long as it occurred within $10 \mathrm{~s}$ of the key being turned on. This 10$\mathrm{s}$ duration was decreased progressively across sessions, in 1-s increments, to $5 \mathrm{~s}$ so long as each trial ended in food.

When the 5-s duration was reached, the first baseline condition commenced. In this first baseline condition, the FR correlated with one of the colors was increased progressively across sessions, in increments of one, for each pigeon separately. An FR 1 remained in effect in the presence of a second color, and extinction was correlated with a third color such that the key was turned on for $5 \mathrm{~s}$, then turned off without food delivery, and $3 \mathrm{~s}$ later the ITI restarted. The key colors correlated with the different trial types were different across pigeons. Three stability criteria were met simultaneously before the next condition began. First, a minimum of 15 sessions occurred, with at least ten consecutive sessions at the same FR values. Second, the percentage of trials ending in food for each stimulus presentation did not exhibit a downward or upward trend, or considerable variability, for a minimum of six consecutive sessions, as assessed by visual inspection. Third, the percentage of trials ending in food under the high FR was considerably less than the percentage of trials ending in food under the FR 1, which was 100\%. Table 1 shows the number of sessions in each condition for each pigeon.

There were two test conditions for each pigeon, with a baseline condition prior to and after each test condition. The details of the procedures in the intervening baseline conditions were as described for the first baseline condition except that the high FR did not change (but see Pigeon 956, Results). Each session of each test condition contained 12 trials, and the same 
sequence of events occurred on each trial in a given test condition. In each test condition, each trial consisted of four key-color presentations and the final presentation always was the key color correlated with the high FR. For each pigeon, the value of the high FR did not change from the preceding baseline condition. The first 3 key colors of each trial differed across test conditions, but each sequence consisted of some combination of two key colors, one correlated with the FR 1 and the other with extinction. There was a 2-s blackout between each stimulus presentation, timed from either the end of food for an FR completion or the end of a 5-s extinction-key presentation, and a key peck in this period restarted the 2-s timer. The type and order of stimulus sequences exposed to each pigeon were different, as shown in Table 1. The stability criteria for reinstating each baseline condition were as described for baseline except that the final criterion was omitted (i.e., the percentage of trials ending in food under the high FR was permitted to vary between 0 and 100).

There is an asterisk in Table 1 for Pigeon 681 in the first baseline condition as this pigeon received training prior to this condition: specifically, prior to this first baseline condition, there was a previous baseline condition followed by a test condition consisting of a multiple schedule. This latter schedule arranged for the concurrent employment of two different sequences. One sequence (extinction-FR 1-FR 1) occurred in the first half of each session, and the second sequence (FR 1-extinction-extinction) occurred in the latter half of each session, with the order of the two sequences random across sessions. There were ten sessions of this multiple-schedule arrangement before its termination. The condition was terminated as it was unclear whether the procedure was testing what it was designed to test.

\section{Results}

The high FR reached in the initial baseline condition for Pigeons 681, 884, and 956 were 18,25 , and 17, respectively. Figure 3 shows the percentage of trials ending in food in the presence of each key color in the final six sessions of each condition for each pigeon. Condition BL refers to the baseline condition and the labels FR and Ext refer to a single FR 1-schedule presentation and an extinction-key presentation, respectively. In the first baseline condition for each pigeon, and in each subsequent condition except where noted, there were no more than two pecks to the key color correlated with extinction for each pigeon in each of the sessions shown. Also, each FR-1 trial ended in food for each pigeon in each session shown. 
Table 1. Order of conditions and number of sessions in each condition (in parentheses) for each pigeon in Experiment 1. In conditions other than baseline are the stimulus sequences that preceded each high FR schedule. FR 1 and Ext refer, respectively, to a fixed-ratio 1 schedule and extinction. See text for details.

$\begin{array}{lll}\text { Pigeon } 681 & \text { Pigeon } 884 & \text { Pigeon } 956\end{array}$

\begin{tabular}{lclllr}
\hline Baseline & $\left(25^{*}\right)$ & Baseline & $(128)$ & Baseline & $(75)$ \\
\multicolumn{2}{l}{ Ext, FR 1, FR 1 (15) } & FR 1, FR 1, Ext (23) & \multicolumn{2}{l}{ FR 1, Ext, FR 1 (18) } \\
Baseline & $(16)$ & Baseline & $(18)$ & Baseline & $(39)$ \\
FR 1, Ext, Ext & $(31)$ & Ext, Ext, FR 1 & $(18)$ & Baseline' & $(46)$ \\
Baseline & $(30)$ & Baseline & $(19)$ & Ext, FR 1, Ext & $(23)$ \\
& & & & Baseline' & $(17)$ \\
\hline
\end{tabular}


Next Page

Figure 3. Percent reinforcers obtained for each pigeon in the final six sessions of each condition in Experiment 1. Triangles show data from the FR 1 schedule. Circles show data from the high FR schedule. Boxes show data from the extinction (Ext) schedule. 
Fig. 3

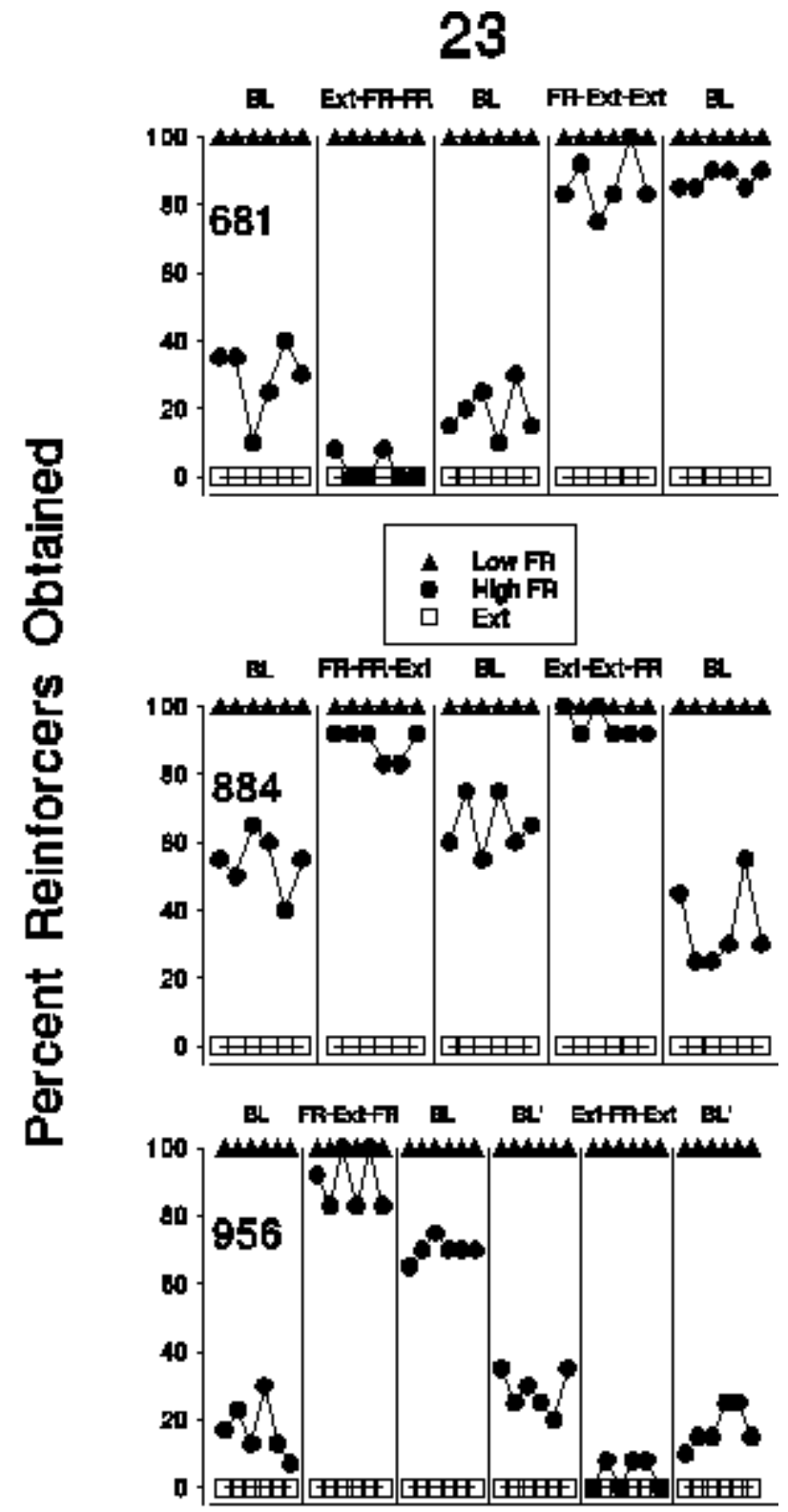

Final Six Sessions 
In the first baseline condition for each pigeon, the percentage of high-FR trials ending in food was lower than the percentage of trials ending in food under the FR 1. In the first test condition, the percentage of high-FR trials ending in food increased relative to baseline for Pigeons 884 and 956, whereas it decreased for Pigeon 681. In the return to baseline, the percentage of high-FR trials ending in food decreased relative to the preceding condition for Pigeons 884 and 956. For Pigeon 956, this decrease resulted in a percentage considerably higher than that observed in the first baseline condition. Also in this return to baseline, relative to the preceding condition, the percentage of high-FR trials ending in food increased for Pigeon 681 to a level comparable to that obtained in the first baseline condition.

Due to the difference in the percentage of high-FR trials ending in food for Pigeon 956 between the first 2 baseline conditions, that FR was increased. Specifically, the FR was changed across sessions, in increments of one, until the percentage of trials ending in food was near its level in the first baseline condition. An FR 19 was reached and remained in effect throughout the remainder of the experiment (baseline' in Table 1 and BL' in Figure 3). In addition, this condition continued until responding stabilized, as defined above (i.e., including the requirement that the FR 19 was in effect for, at least, the final six sessions of the condition).

In the second test condition, the percentage of high-FR trials ending in food for Pigeons 681 and 884 increased relative to the preceding baseline condition, whereas it decreased for Pigeon 956. In addition, for Pigeon 956 the number of red-key pecks increased substantially in this condition, averaging 138.17 across the final six sessions $(\mathrm{SD}=28.30)$. In the final baseline condition, the percentage of high-FR trials ending in food, relative to the preceding condition, remained the same for Pigeon 681, decreased for Pigeon 884, and increased for Pigeon 956. In addition, there were no extinction-key pecks for Pigeon 956 in any of the final six sessions of the final baseline condition.

\section{Discussion}

The results of Experiment 1 were mixed across pigeons. For Pigeon 884, two different stimulus sequences (i.e., FR 1-FR 1-extinction and extinction-extinction-FR 1) increased responding under a high FR similarly. For the other two pigeons, however, each of two different stimulus sequences changed responding in opposite ways, such that one increased responding and the other decreased responding. There is a caveat, however, when considering these latter 
results. For Pigeon 681, although responding increased following the execution of its second sequence, responding did not return to its baseline level following its removal. And for Pigeon 956, a disruption in stimulus control accompanied the decrease in responding following the implementation of its second sequence; that is, extinction-key pecking increased substantially from baseline, and as this result did not occur with the first sequence, its role in interpreting the results is unclear. Thus, the present results do not aid in distinguishing between different interpretations of the results from Pigeon Model 2.

\section{Experiment 2}

Discussed above was the prediction derived from the proposed, response-activation interpretation that the effects of a food-delivery sequence depend on the reinforcement schedule in effect following such a sequence. It was suggested that pecking increased under the high FR in both pigeon models due to the coupling arranged by that schedule; that is, multiple key pecks preceded each reinforcer delivered previously under that schedule. The purpose of Experiment 2, therefore, was to assess the effects of a food-delivery sequence on responding under a VI schedule. As the coupling arranged under a VI schedule is lower than that arranged under an FR schedule (Killeen, 1994), the prediction based on the proposed account is that pecking will not increase in Experiment 2 to the extent that it did in the pigeon models.

In addition to testing the above prediction, Experiment 2 also is relevant in interpreting the effects of reinforcement rate on responding following a food-delivery sequence. When responding increased under the high FR in both pigeon models, so did its correlated rate of reinforcement. The relative impact of this increased reinforcement rate versus that of the preceding sequence, therefore, is unknown. In Experiment 2, however, response-rate changes under the VI schedule will affect reinforcement rate minimally (cf. Catania \& Reynolds, 1968). Thus, if responding following a sequence of food deliveries is controlled only by the rateincreasing effects of that sequence, then responding ought to increase under the VI schedule. If, however, this responding is controlled by both the preceding sequence and a subsequent increase in reinforcement rate correlated with that responding, then response rates should remain unchanged under the VI schedule. 


\section{Method}

\section{Subjects and Apparatus}

Three White Carneau pigeons with various experimental histories were maintained as in Experiment 1. An apparatus similar to the one described for Experiment 1 was used except it had one response key (2-cm diameter and centered on the front wall), the hopper was directly below the key, and the houselight was on the ceiling.

\section{Procedure}

Phase 1. The first baseline condition commenced immediately following autoshaping and was similar to the baseline condition of Experiment 1 with the following exceptions. On 30 of the 60 trials, a red key was presented, and on the other 30 trials a white key was presented. The red key was correlated with an FR 10 such that its completion within $10 \mathrm{~s}$ of the key being turned on resulted in 3-s access to grain, and its noncompletion resulted in its darkening and, $3 \mathrm{~s}$ later, the start of the ITI. A VI 150-s schedule was correlated with the white key and each trial lasted a maximum of $10 \mathrm{~s}$. Specifically, if the current interval timed out, the next key peck resulted in 1.5-s access to grain and termination of the trial. The VI schedule consisted of 10 intervals derived from the distribution described by Fleshler and Hoffman (1962). In each baseline session, each key color occurred twice in each of the fifteen 4-trial blocks, and their order in each block was random. Each baseline condition continued until two stability criteria were met simultaneously: first, a minimum of 15 sessions occurred, and second, response rates under each schedule did not exhibit a downward or upward trend, or considerable variability, for a minimum of six consecutive sessions, as assessed visually. Table 2 shows the number of sessions in each condition for each pigeon.

There were two test conditions for each pigeon and a baseline condition intervened between each. There were 12 trials in each session of each test condition. In one test condition, on six of the trials, three red-key presentations preceded a white-key presentation, and on the other six trials four red-key presentations preceded a white-key presentation. Food was delivered following each FR completion and $2 \mathrm{~s}$ intervened between the end of food for one FR completion and the next stimulus presentation, including the white key. In the other test condition, on six of the trials, three response-independent food deliveries preceded a white-key presentation, and on the other six trials, four response-independent food deliveries preceded a white-key presentation. 
Table 2. Order of conditions and number of sessions in each condition (in parentheses) for each pigeon in Experiment 2. In conditions other than baseline in each phase are the stimulus sequences that preceded each VI schedule. RDF and RIF refer, respectively, to a sequence of fixed-ratio 10 schedules and response-independent food deliveries. See text for details.

$\begin{array}{ll}\text { Pigeon } 422 \quad \text { Pigeon } 932 & \text { Pigeon } 946\end{array}$

Phase 1

Baseline (40)

Baseline (40)

Baseline (40)

RDF (18)

RDF (25)

RIF

Baseline (18)

Baseline (15)

Baseline (17)

RIF (15)

RIF

RDF (16)

Baseline (16)

Baseline (21)

Baseline (18)

RIF (20)

Phase 2

Baseline (20)

Baseline (19)

Baseline (15)

RDF (16)

RDF

(23)

RIF

Baseline (61)

Baseline (43)

Baseline (15)

RIF

RIF

RDF

Baseline (25)

Baseline (25)

Baseline (18)

RIF 
In this latter test condition, the key light and houselight remained dark throughout the responseindependent sequence. Each test condition continued until the stability criteria described for the baseline condition were met, and their order was different across pigeons, as shown in Table 2 .

Phase 2. Although the same VI schedule was in effect during both baseline and the test conditions of Phase 1, there were fewer VI trials in the test conditions than in baseline. For that reason, it was possible for the obtained reinforcement rate under the VI schedule to be slightly lower in the test conditions relative to baseline (see also, Results). Therefore, Phase 2 was conducted to assess the validity of the results from Phase 1 by ensuring that the same VI schedule and the same number of VI trials occurred in each session of both baseline and the test conditions.

Phase 2 was similar to Phase 1 with the following exceptions. In each baseline session, there were 24 trials instead of 60. On 12 trials, the red key was presented with its correlated FR 10 , and a VI 60-s schedule was correlated with the white key on the other 12 trials. Also in each baseline session, each key color occurred three times in each of the five 6-trial blocks. The operation of the test conditions was identical to Phase 1 except the VI 60-s schedule was correlated with the white key. Table 2 shows the number of sessions in each condition for each pigeon.

\section{Results}

\section{Response rates}

Figures 4 and 5 shows response rates (i.e., pecks per second) to each key color for each pigeon in the final six sessions of each condition in Phases 1 and 2, respectively. For Experiment 1 and Pigeon Models 1 and 2, response rates were not displayed graphically (only the proportion of trials ending in food was) as it was necessarily true that response rates increased if the proportion of trials ending in food increased. As no such correspondence exists under a VI schedule, response rates for this experiment are shown graphically. In Figure 4, BL refers to baseline, and RDF and RIF refer, respectively, to when the VI schedule was preceded by a sequence of response-dependent food deliveries (FR-schedule presentations) and responseindependent food deliveries. The range on the y-axis for Pigeon 932 is different than on the other graphs. 
Next Page

Figure 4. Pecks per second for each pigeon in the final six sessions of each condition in Phase 1 of Experiment 2. Triangles show data from the FR 10 schedule. Circles show data from the VI 150-s schedule. BL refers to baseline, and RDF and RIF, refer, respectively, to when the VI schedule was preceded by a sequence of response-dependent food deliveries provided for completing the FR schedule or response-independent food deliveries. 
Fig. 4

30

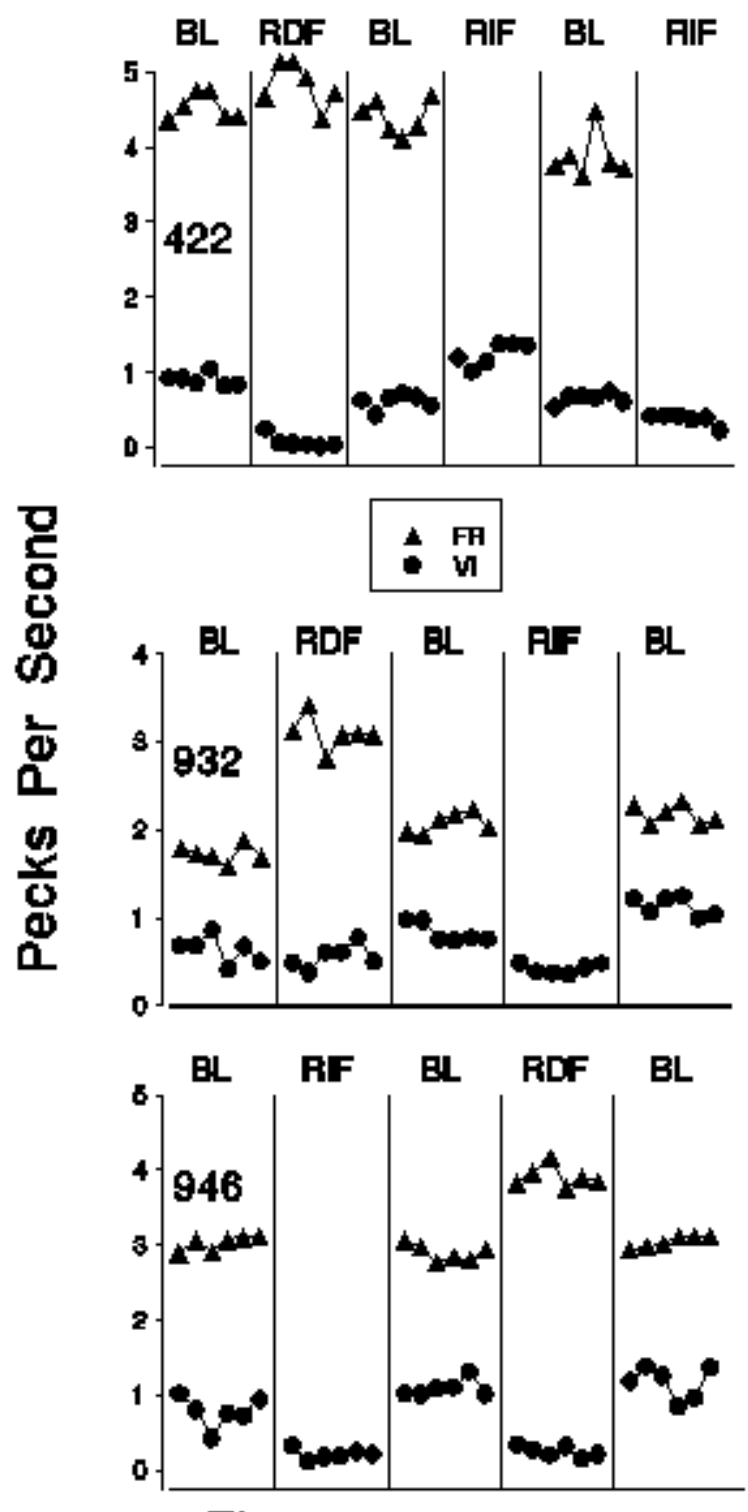

Final Six Sessions 


\section{Next Page}

Figure 5. Pecks per second for each pigeon in the final six sessions of each condition in Phase 2 of Experiment 2. Triangles show data from the FR 10 schedule. Circles show data from the VI 60-s schedule. BL refers to baseline, and RDF and RIF refer, respectively, to when the VI schedule was preceded by a sequence of response-dependent food deliveries provided for completing the FR schedule or response-independent food deliveries. 
Fig. 5

32
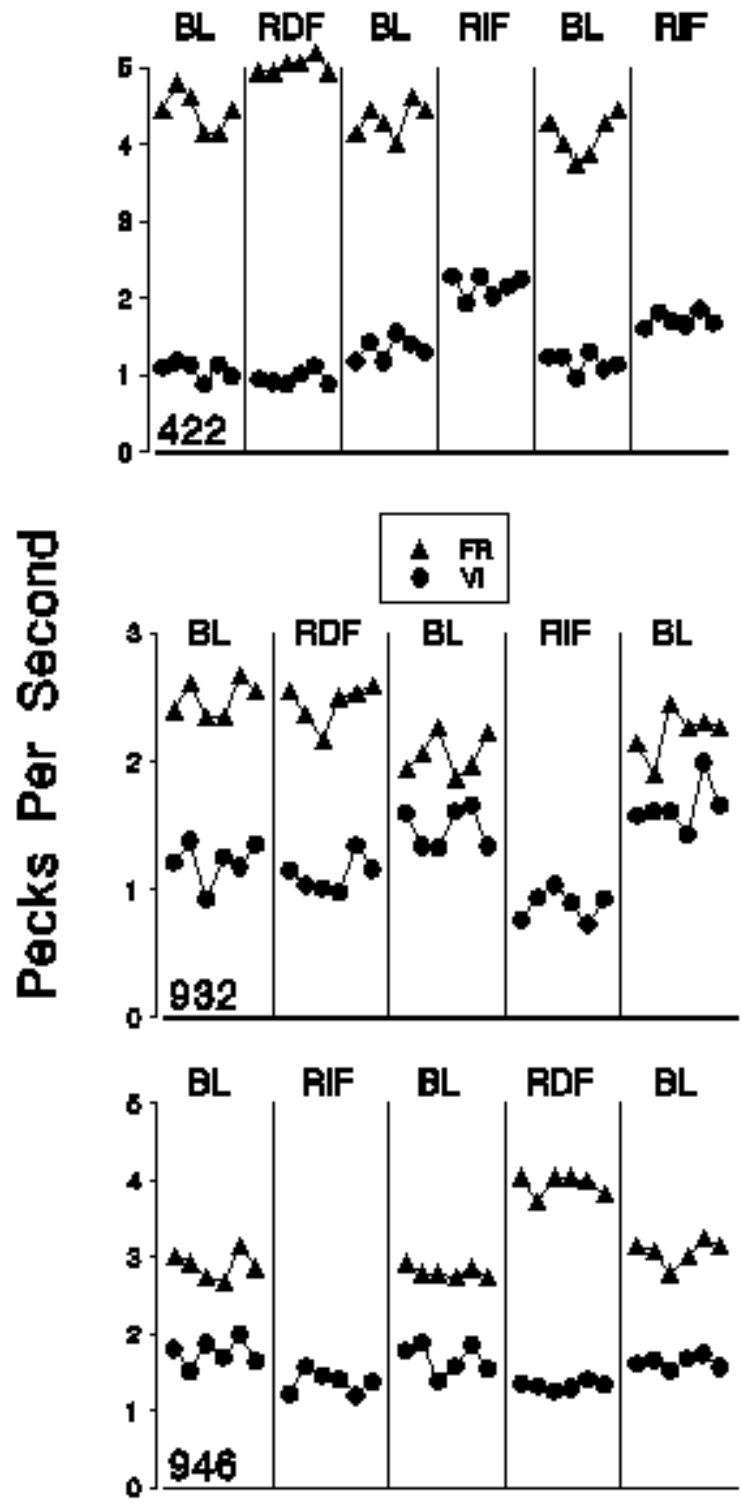

Final Six Sessions 
In each session shown of each condition for each pigeon, response rates were higher under the FR than the VI schedule. For each pigeon, there was relatively little change in response rates under either schedule across baseline conditions. Relative to baseline, for Pigeons 932 and 946, FR-schedule response rates increased in Condition RDF, whereas this result is less clear for Pigeon 422. Also in Condition RDF, VI-schedule response rates decreased from baseline for Pigeons 422 and 946 and remained the same for Pigeon 932. In Condition RIF, VI-schedule response rates decreased relative to baseline in each instance except one (Pigeon 422, first exposure).

In Figure 5, the condition labels are the same as in Phase 1, and the range on the y-axis for Pigeon 932 is different than on the other graphs. As in Phase 1, for each pigeon, response rates were higher under the FR than the VI schedule in each session shown of each condition, and there was relatively little change in response rates under either schedule across baseline conditions. For Pigeons 422 and 946, FR-schedule response rates were higher in Condition RDF than in baseline, whereas these rates were similar for Pigeon 932. Also in Condition RDF, VIschedule response rates were similar to their baseline level for each pigeon. In Condition RIF, relative to baseline, VI-schedule response rates increased for Pigeon 422 in each of two exposures, decreased for Pigeon 932, and remained the same or decreased slightly for Pigeon 946.

\section{Percent reinforcers obtained}

Figure 6 shows the percentage of trials ending in food for each pigeon in the final six sessions of each condition in Phases 1 (left graphs) and 2 (right graphs). The range on the y-axis for Pigeon 946 in Phase 1 is different than on the other graphs for Phase 1. There was little difference in the percentage of trials ending in food across conditions in Phase 1, with two exceptions. First, this percentage may have been slightly lower in the test conditions than in the baseline conditions, as there were relatively more test sessions without a reinforcer delivery. Second, for Pigeon 422, more reinforcers occurred in the final six sessions of the first Condition RIF than in the final six sessions of the second Condition RIF, and this result may have been responsible for the response-rate difference between the two conditions (Figure 4). In Phase 2, the percentage of trials ending in food for each pigeon was similar across all sessions. 
Next Page

Figure 6. Percent reinforcers obtained under the VI schedules for each pigeon in the final six sessions of each condition in Phases 1 (left graphs) and 2 (right graphs) of Experiment 2. 
Fig. 6

Phase $1 \quad 35$ Phase 2

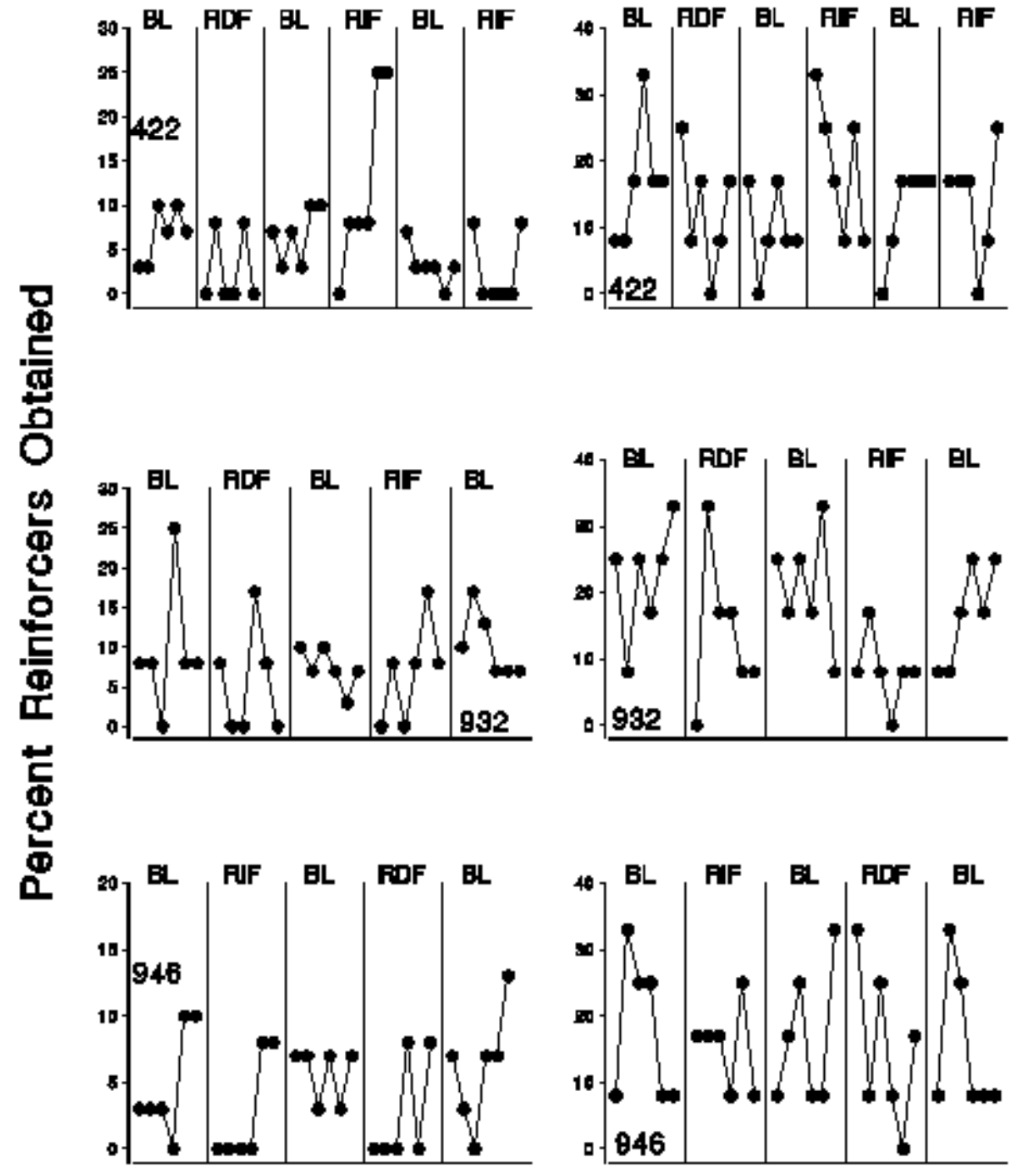

Final Six Sessions 


\section{Discussion}

The results of each phase in Experiment 2 generally were similar, and there were two main findings. First, VI-schedule response rates did not increase reliably, relative to baseline, following a sequence of closely presented food deliveries. This result occurred regardless of whether the deliveries were response dependent or independent (but see Pigeon 422, Phase 2). Second, FR-schedule response rates increased, relative to baseline, during the execution of the former sequence. This second result probably is attributable to the increase in reinforcement rate during this test condition, relative to baseline.

At least two implications follow from the finding that VI-schedule response rates did not increase reliably in the test conditions as a function of the preceding sequence of food deliveries. First, this finding supports the notion that the effects of such a sequence are modulated by the reinforcement schedule in effect, thereafter. This notion is consistent with an appeal to the coupling principle and, thus, lends support to the proposed interpretation based on Killeen's (1994) framework. Second, due to the discrepant results between Pigeon Model 1 and Experiment 2, the response-rate increase observed in that model probably was the result of both the food-delivery sequence and the increased reinforcement rate correlated with responding under the high FR schedule. A caveat to consider with this former conclusion, however, is that these discrepant results also occurred with different pigeons.

Despite the agreement between the present results and the proposed interpretation, the results could be described in other ways, although the predictions of a behavioral-momentum or establishing-operations account for Experiment 2 are unclear. Thus, the third experiment was conducted to distinguish between these various interpretations, as well as to assess further the role of the reinforcement schedule in effect following a sequence of food deliveries.

\section{Experiment 3}

There were two aims of Experiment 3: to distinguish between the various interpretations of compliance change thus far discussed, and to assess further how the effects of a food-delivery sequence are modified by the reinforcement schedule in effect thereafter. Recall that according to a behavioral-momentum account of the high-p procedure, the reinforcement provided during a high-p sequence increases the momentum of compliance such that it persists against the disrupting effects of a low-p request. Given the tenuous standing of this account, however (see 
Literature Review), it was pitted in Experiment 3 against the modified account of compliance change discussed above, based on Killeen's (1994) reinforcement principles. In Experiment 3, the effects of a food-delivery sequence were investigated on subsequent responding under a variant of a differential-reinforcement-of-low-rate (DRL) schedule, such that food was delivered only if a peck followed a fixed period of time after the key-light onset. To satisfy a behavioralmomentum account, response efficiency on DRL trials should increase as a function of the highp sequence as this sequence ought to enhance any member of the response class compliance. On the other hand, it has been asserted that the inefficient pecking of pigeons on DRL schedules is, in part, the function of arousal such that a manipulation that enhances arousal ought to decrease response efficiency (cf. Doughty \& Richards, 2002). Thus, if the present food-delivery sequences increase arousal, then such sequences should generate less efficient DRL-schedule responding.

In Pigeon Model 1, an FR schedule was in effect following the food-delivery sequence such that its correlated reinforcement rate increased when responding increased. Due to the operation of a VI schedule in Experiment 2, any response-rate increases affected reinforcement rate minimally, and, perhaps consequently, response rates did not change greatly. In Experiment 3 , due to the operation of a DRL schedule, any response-rate increase, following a sequence of food deliveries, would decrease its correlated reinforcement rate. Thus, by comparing results across these three experiments, a greater understanding of the consequent conditions controlling compliance change may be elucidated.

\section{Method}

\section{Subjects and Apparatus}

Three White Carneau pigeons with various experimental histories were maintained as in Experiments 1 and 2, and an apparatus similar to the ones described for those experiments was used. The chamber contained three response keys (each 2-cm diameter), the hopper was located directly below the center key (the only key used), and the houselight was located in the lower right corner of the front wall.

\section{Procedure}

Training commenced with autoshaping to each of two key colors (green and white), followed by a training condition similar to the training conditions of the first 2 experiments. After a 60-s ITI, both the key light and houselight were turned on such that there were 30 green- 
key and 30 white-key trials. Each key color occurred twice in each of the fifteen 4-trial blocks, and their order within each block was random. In the presence of one color, a single key peck produced immediate access to grain for $3 \mathrm{~s}$ (i.e., FR 1), after which the ITI restarted. If a peck did not occur for $5 \mathrm{~s}$, however, then both the key light and houselight were darkened and, $3 \mathrm{~s}$ later, the ITI restarted. A variant of a DRL 5-s schedule was correlated with the other color such that a peck before the 5 -s criterion, timed from the onset of the key light, darkened both the key light and houselight, and food was not presented. If $5 \mathrm{~s}$ passed without a peck, then the next peck produced immediate access to grain for $3 \mathrm{~s}$, after which the next ITI began. In this condition, as well as in each subsequent condition, a peck prior to the DRL criterion extended the following ITI for some time, calculated by subtracting the latency to that peck from the DRL criterion. The color of the keys correlated with the FR and DRL schedules was different across pigeons.

The next condition was designated the first baseline condition, and all details were the same as in the preceding condition except that the DRL criterion changed across its initial sessions. The DRL criterion was changed for each pigeon separately, across sessions and in 1-s increments, until considerably fewer than $100 \%$ of the trials ended in food. Instead of utilizing a DRL criterion that resulted in approximately $15-25 \%$ of the trials ending in food, as in the previous experiments, a criterion was used that produced a percentage higher than $25 \%$ but still less than $100 \%$. This different criterion allowed for changes in the percentage of trials ending in food in subsequent test conditions to be assessed in the absence of any floor effects. After this percentage was reached the effective DRL criterion remained in effect throughout the experiment. Each baseline condition continued for a minimum of 15 sessions and until stable responding occurred. Stability criteria ensured that there was no downward or upward trend, or considerable variability, in the percentage of trials ending in food under each schedule, as assessed visually. An additional criterion, in effect only for the first baseline condition, ensured that the same DRL criterion was in place, for each pigeon, across those same six sessions. Table 3 shows the order of conditions and the number of sessions in each for each pigeon.

There were two test conditions for each pigeon, and a baseline condition preceded and followed each test condition. There were 15 trials in each session of each test condition, and each trial was preceded by a 60-s ITI. In one test condition, on each trial a DRL presentation was preceded by three FR presentations. Food was delivered following an FR completion and $2 \mathrm{~s}$ 
Table 3. Order of conditions and number of sessions in each condition (in parentheses) for each pigeon in Experiment 3. In conditions other than baseline are the stimulus sequences that preceded each DRL schedule. RDF and RIF refer, respectively, to a sequence of fixed-ratio 1 schedules and response-independent food deliveries. See text for details.

$\begin{array}{ll}\text { Pigeon } 247 & \text { Pigeon } 619\end{array}$

\begin{tabular}{lll}
\multicolumn{2}{l}{ Baseline (33) } & \multicolumn{2}{l}{ Baseline (39) } & \multicolumn{2}{l}{ Baseline (70) } \\
RIF (19) & RDF (27) & RDF (38) \\
Baseline (15) & Baseline (21) & Baseline (30) \\
RDF (16) & RIF (90) & RIF (16) \\
Baseline (15) & Baseline (15) & Baseline (20)
\end{tabular}


intervened between the end of one food delivery and the next key-light onset, including the DRL. A constant number of FR presentations preceded a DRL presentation, as opposed to varying between three and four as in the previous experiments, to increase the "discriminability" of the DRL presentation (i.e., to help prevent an "accidental" peck on a DRL trial).

The other test condition was similar to the one previously described except that three response-independent food deliveries preceded each DRL presentation, instead of the three FR presentations. The key light and houselight remained dark throughout this response-independent sequence and $2 \mathrm{~s}$ intervened between the end of one food delivery and the start of the next, as well as between the end of the final delivery of each sequence and the start of the DRL presentation. Stability in each test condition was as in the baseline conditions.

\section{Results}

Figure 7 shows the percentage of trials ending in food under each schedule in the final six sessions of each condition for each pigeon. The DRL criteria in each session shown in Figure 7 for Pigeons 247, 619, and 964 were 6, 14, and 24 s, respectively, and the significance of the condition labels is as in Experiment 2. For each pigeon, the percentage of FR trials ending in food was 100\% in each session except one (Pigeon 964, Condition B), and in each session, the percentage of DRL trials ending in food was considerably less than $100 \%$. The results for Pigeons 247 and 964 were similar: the percentage of DRL trials ending in food was similar across each baseline condition and lower than baseline in each test condition. This percentage was similar in the two test conditions for Pigeon 247 and slightly lower in Condition RIF, relative to Condition RDF, for Pigeon 964. For Pigeon 619, the percentage of DRL trials ending in food decreased relative to baseline in Condition RDF, and then increased slightly in the return to baseline. In Condition RIF, the percentage of DRL trials ending in food increased relative to the preceding baseline and then remained unchanged in the final baseline condition.

Figure 8 shows the mean (and standard deviation) latency to peck under the DRL schedule across the final six sessions of each condition for each pigeon. For each condition, the mean latency for each of the six sessions first was calculated, and the mean of those six means then was graphed. Each standard deviation, therefore, shows the variability around this latter mean and is relatively small in each condition. The dotted, horizontal line in each graph shows the DRL criterion for each pigeon, and as these criteria were different across pigeons the ranges 
Next Page

Figure 7. Percent reinforcers obtained for each pigeon in the final six sessions of each condition in Experiment 3. Triangles show data from the FR 1 schedule. Circles show data from the DRL schedule. BL refers to baseline, and RDF and RIF refer, respectively, to when the DRL schedule was preceded by a sequence of response-dependent food deliveries provided for completing the FR schedule or response-independent food deliveries. 
Fig. 7

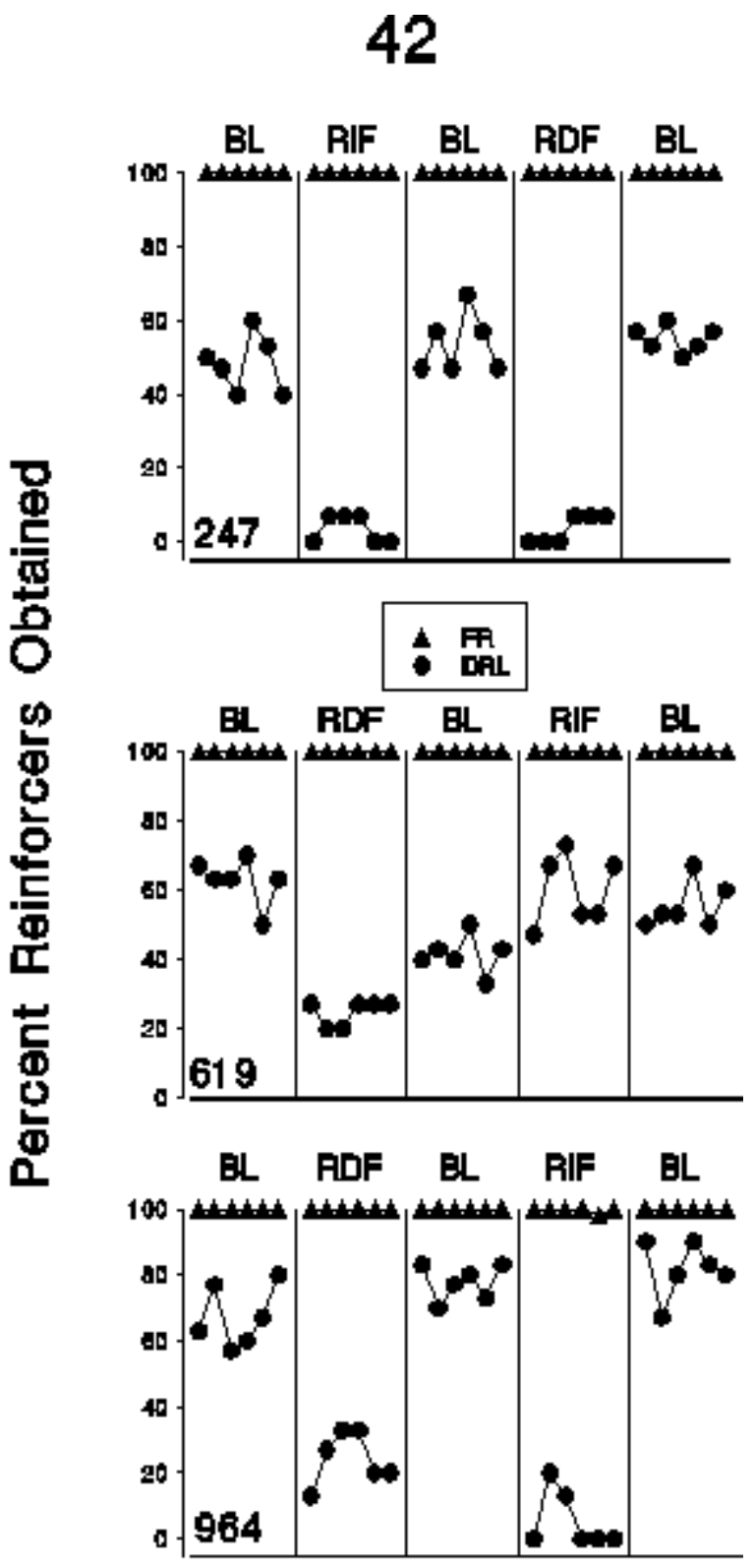

Final Six Sessions 
Next Page

Figure 8. Mean latency (in seconds) for each pigeon across the final six sessions of each condition in Experiment 3. Error bars show standard deviations, and the dotted, horizontal lines show the DRL criterion for each pigeon. 
Fig. 8
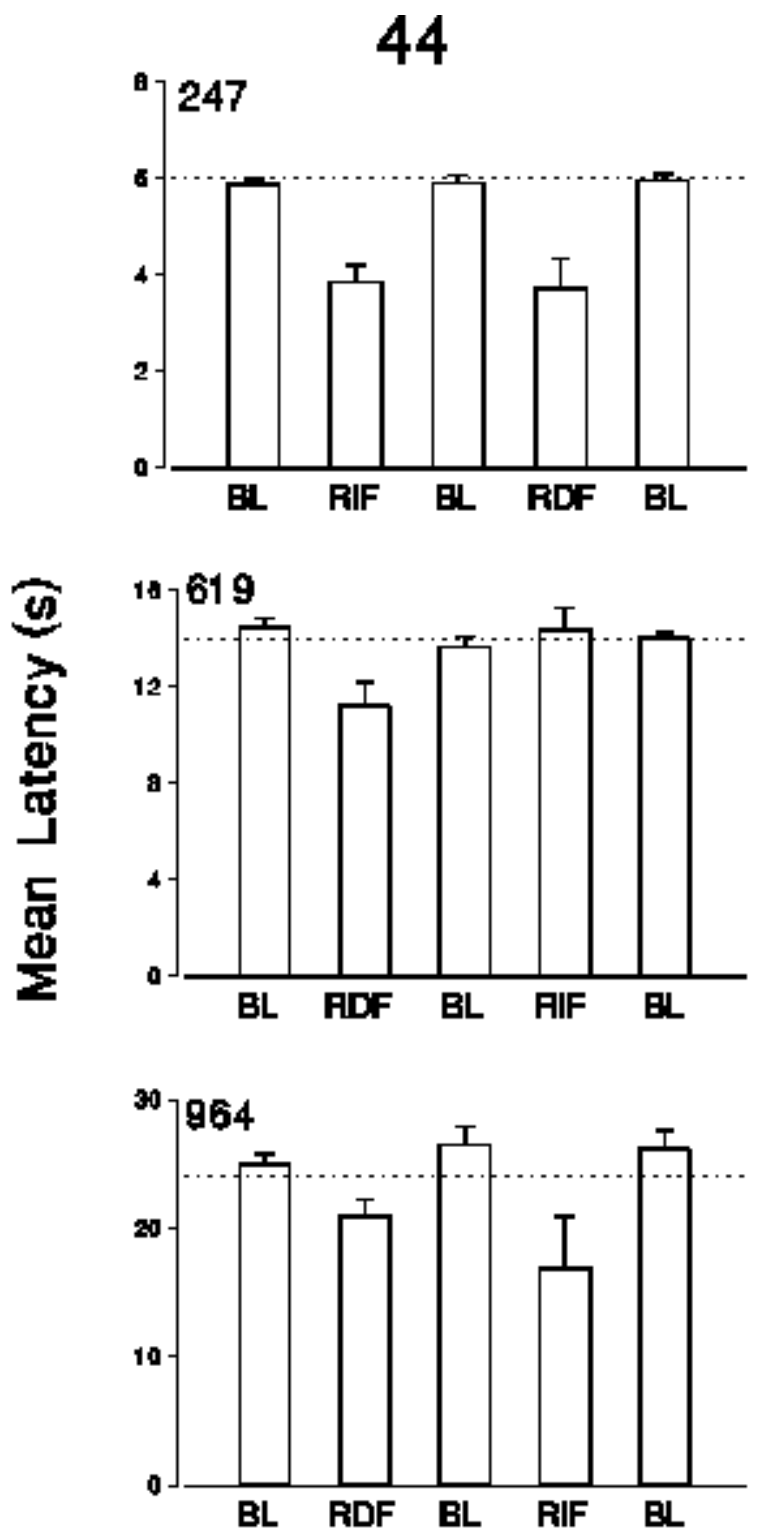

Final Six Sessions 
on each graph are different. The mean latency to peck in each baseline condition was at or slightly above the DRL criterion, whereas it was relatively lower in each test condition, with one exception (Pigeon 619, Condition RIF).

For Pigeon 619 in Condition RIF, not only did responding change in a way opposite to that of the other test conditions (Figures 7 and 8), but response variability also increased. That is, stability was not reached for a relatively lengthy period of time (90 sessions, Table 3 ), and when responding was stable the variability in trials ending in food was greater than it had been in previous conditions (Figure 7).

\section{Discussion}

In five of six conditions, DRL-schedule responding was less efficient when preceded by three closely presented food deliveries, relative to when the deliveries were omitted. In addition, this result occurred whether the deliveries were response dependent or independent. This decreased efficiency was indexed by both the percentage of DRL trials ending in food and the latency to peck on these trials. Thus, these findings relate to the different interpretations offered for compliance change discussed above and the importance of considering the consequent conditions in effect following these food-delivery sequences. That response efficiency decreased under the DRL schedule as a function of the food-delivery sequences is inconsistent with a behavioral-momentum interpretation of the high-p procedure. This result, however, is consistent with the notion that such sequences elevate arousal, or activity, which then is modulated by the reinforcement schedule in effect (see also below, General Discussion). Finally, and related to the latter point, that discrepant results were obtained across Pigeon Model 1, Experiment 2, and this experiment, shows that to predict the effects of a sequence of food deliveries it is necessary to consider the reinforcement schedule in effect thereafter. As noted above, however, there is a caveat to consider when interpreting these results as they were obtained with different pigeons.

Two alternative accounts of the results of Experiment 3 should be discounted before the above interpretation is accepted. First, it is noteworthy that the mean latency on DRL trials only decreased by a few seconds, rather than dropping to near-zero levels. That such latencies did not decrease to near-zero levels suggests that the key-light onset still controlled DRL responding and only that its efficiency had decreased. On the other hand, if latencies had decreased to near-zero levels, then an alternative account would have been plausible, for example, escape from an 
aversive stimulus. The second account to be discounted is that DRL-schedule responding was made less efficient through an alteration in "timing," as such responding depends on reinforcement rate (e.g., Bizo \& White, 1994). Two arguments discount this timing account. First, although there was a relatively substantial increase in reinforcement rate between the baseline and test conditions, several sessions of exposure to this higher reinforcement rate occurred such that timing should have been controlled by this higher rate after some period of time. Second, research suggests that DRL-schedule responding is not governed solely by a timing process as particular manipulations (e.g., changes in reinforcer magnitude) affect responding differently under a DRL schedule relative to procedures designed to study timing per se (cf. Doughty \& Richards, 2002).

The findings in Figure 9 support the claim that the results of Experiment 3 are not due to altered timing under the DRL schedule. Pigeon 247 was exposed to procedures similar to Experiment 3 except that a differential-reinforcement-of-other-behavior (DRO) 6-s schedule replaced the DRL 6-s schedule. Therefore, on a DRO trial, food delivery was dependent on the absence of a key peck for $6 \mathrm{~s}$, whereas a key peck before that criterion ended the trial. The findings were nearly identical to the results of Experiment 3, even though responding was not required under the DRO and, thus, could not be influenced by timing. Thus, although this latter finding was obtained with only one pigeon, it suggests that the results of Experiment 3 were not due to altered timing under the DRL schedule as a function of the food-delivery sequences. Chapter 3 - Conclusions

\section{General Discussion}

Two experiments designed to model, with pigeons, several compliance techniques studied in applied behavior analysis and social psychology were described in the literature review. Three experiments then were conducted to determine some of the variables responsible for the behavior change observed in those earlier pigeon models, as well as to distinguish between various interpretations of that behavior change. Taken together, the results showed that the probability of completing a schedule requirement depended on both the presence or absence of a preceding sequence of events and the reinforcement schedule in effect following such sequences. Specifically, the efficiency of FR-schedule performance was enhanced as a function 
Next Page

Figure 9. The top graph shows the percent reinforcers obtained for Pigeon 247 in the final six sessions of each of four conditions. Triangles and circles show data from the FR 1 and DRO 6-s schedules, respectively. The bottom graph shows the mean latency (in seconds) for the same pigeon in the same sessions. Error bars show standard deviations, and the dotted, horizontal line shows the DRO criterion. In each graph, BL refers to baseline, and RDF and RIF refer, respectively, to when the DRO schedule was preceded by a sequence of response-dependent food deliveries provided for completing the FR schedule or response-independent food deliveries. 
Fig. 9

48
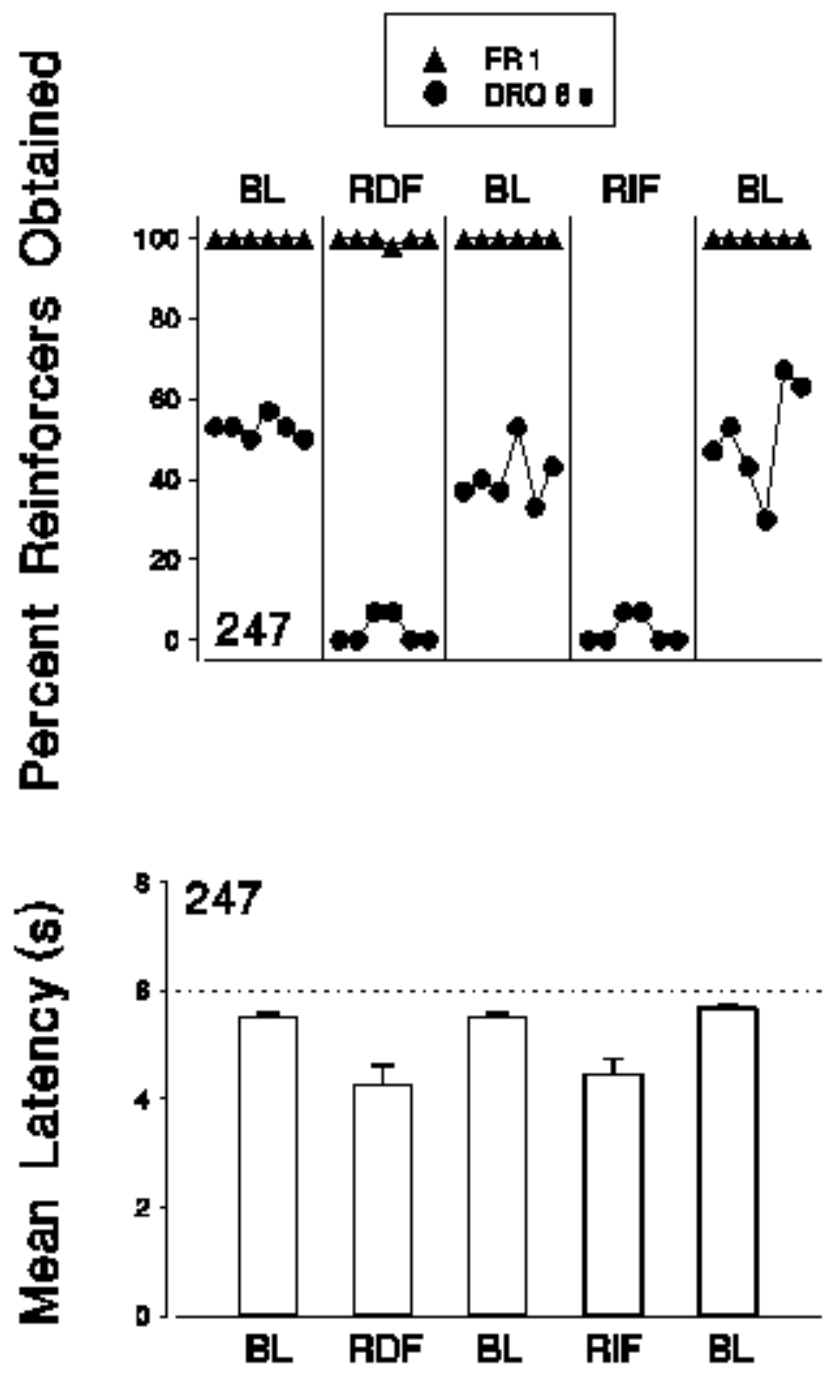

Final Six Sessions 
of either a preceding food-delivery sequence (Pigeon Model 1) or a sequence of extinction-key onsets (Pigeon Model 2). Such a food-delivery sequence, however, had little effect on VIschedule responding (Experiment 2) and decreased the efficiency of DRL-schedule responding (Experiment 3). The effects of sequences containing both an FR-1 schedule presentation and an extinction-key presentation, however, produced inconclusive results (Experiment 1). Discussed below, therefore, are a behavioral conceptualization of compliance, the value of animal models of compliance, the study of compliance as a link between basic and applied behavior analysis, and between behavior analysis and social psychology, different accounts of compliance change, concerns surrounding animal compliance, and future compliance research.

A behavioral conceptualization of compliance. Behavior analysts have been criticized for ignoring "complex human behavior" (cf. Skinner, 1974), and, given that compliance falls under this aforementioned category, it is imperative that behavior analysts provide their own account of the environment-behavior relations subsumed by that term. To describe compliance in the context of the three-term contingency, a request is an antecedent stimulus, the requested response is the second term, and the consequences are provided by the individual presenting the request and/or are produced by the compliant behavior itself. In addition, for the term compliance to apply, the response must be controlled, in part, by the request, and these two events typically must co-occur within a specified period of time. Thus, compliance is a label given to a particular type of discriminated operant behavior.

The value of animal models of compliance. Two issues related to the utilization of animal subjects in psychology in general are simplicity and ethics, and each of these issues relates to the development of animal models in particular. Stimuli (e.g., key lights) and responses (e.g., key pecks) in typical psychology experiments using animals are both easily controlled and measurable. In addition, when attempting to isolate particular variables, some environmental conditions may be controlled more readily with animals than with humans. This latter point also bears on an ethical issue. Consider the research presented above wherein one goal was to assess the function of the consequences supporting low-p compliance in the execution of the high-p procedure. Typically, when low-p compliance increases so does its correlated reinforcement rate, and it was unclear what the role of this increased reinforcement rate was in the efficacy of the high-p procedure. To investigate this variable by withholding such reinforcement for a human 
with a long history of noncompliance seems unethical, or at least impractical. This variable, however, was studied in the present set of experiments with animals, and, in fact, it was demonstrated that this increased reinforcement rate is a necessary component in the efficacy of the high-p procedure.

Given the above argument that animal models in general are useful in the conduct of behavioral research, the next issue concerns the plausibility of developing animal models of compliance, in particular. This issue is noteworthy especially given the reliance thus far of defining the antecedent stimulus in an episode of compliance as a spoken request. Although compliance typically involves a spoken request, it is not necessary as the term also describes the correspondence between a written or gestured request and a subsequent response, for example, when a nurse complies with a doctor's written directions (cf. Cohen \& Davis, 1981, as cited in Cialdini, 1995). Thus, the label compliance need not be reserved for situations consisting of spoken requests, and, as such, the functional differences between a colored key to a pigeon and words on a paper to a human seem minimal (see also Lattal \& Doepke, 2001).

If a colored-key-light presentation to a pigeon may be deemed a request, then the next issue is the distinction between "animal compliance" and other instances of "scheduleappropriate" responding of animals. In other words, under what conditions may the operant behavior of an animal appropriately be labeled compliant? It may be that the procedures used to study such behavior are an integral component in applying the label compliance, and the argument supporting this assertion is as follows. Discriminated operant behavior simply is some bit of responding occasioned by a discriminative stimulus and maintained by its consequences, and this behavior may take a wide variety of forms. To account for this variety in form, and so that the prediction, control, and interpretation of behavior may be facilitated, different labels are used to characterize different environment-behavior relations (e.g., remembering, attending, categorizing, etc.). Furthermore, these terms apply to both human and animal behavior, and both structural and functional criteria are used to justify the correspondence of these labels between human and animal behavior (cf. Lattal, 2001). Structural criteria concern the form of the environment-behavior relations under investigation, and functional criteria concern the environmental variables controlling such behavior. Functional similarities between human compliance change and the behavior change observed in the present experiments are discussed 
below (see Different accounts of compliance change), and the structural similarities between them are presented next.

Numerous aspects of the present experiments mirror the events occurring in a typical episode of compliance with humans. First, a requested response (e.g., the completion of an FR requirement) did not occur in the absence of its correlated request (i.e., a key-light presentation). Second, shortly after this request was presented, the requested response either did or did not occur. And finally, a reinforcer was dependent on the occurrence of the requested response. As it is difficult to argue against a formal correspondence between these listed events and those events occurring in a typical episode of human compliance, it seems that the structural criteria of developing animal models of compliance have been satisfied in the present experiments. The study of compliance as a link between basic and applied behavior analysis, and between behavior analysis and social psychology. There are numerous reasons supporting the claim that animal models of compliance are useful to applied behavior analysts. Such modeling, for instance, may allow for the control necessary to isolate the variables underlying applied compliance techniques (e.g., Mace et al., 1997), and this isolation bears on at least two issues. First, if these variables were identified, the application of such techniques could be made more efficient and/or more effective by reducing unnecessary components and/or by enhancing the necessary ones. Second, novel compliance techniques taking into account those essential variables may be devised.

To illustrate how the present results bear on the development of novel compliance techniques, consider the results of Ardoin, Martens, and Wolfe (1999). These authors utilized the high-p procedure to decrease the latency of three children in the transition from one school activity to another. A similar but novel treatment, employing both the high-p procedure and door in the face, would involve the occasional arrangement used by Ardoin et al., as well as the occasional request for the target activity shortly after noncompliance with a severe request. A second, novel treatment would include a modification to door in the face: following several highp requests, two requests could be presented to the students simultaneously, one severe and the other correlated with the target activity itself.

Finally, to illustrate a case in which door in the face may be relatively more effective than the high-p procedure, consider food refusal (e.g., Anderson \& McMillan, 2001; Freeman \& 
Piazza, 1998). It may be, for example, that the consumption of a particular, nonpreferred item is more likely following noncompliance with a request to consume an even less-preferred item.

The development of the above treatments containing door in the face, either in conjunction with the high-p procedure or in its place, is invited partly by the finding that compliance with high-p requests sometimes decreases across training and that this reduction may be due to satiation (cf. Davis \& Reichle, 1996). By alternating between high-p requests and severe requests, this satiation may be attenuated, as there would be fewer reinforcers delivered. And as such, a high level of compliance may occur for a longer time. Furthermore, the above suggestion that door in the face may be more effective at reducing food refusal than the high-p procedure is based partly on the notion that satiation may occur rapidly if food reinforces compliance with high-p requests.

The link between the present, modeled techniques, the application of the high-p procedure, and other basic-behavior-analytic research may be illustrated by considering the results of Perone and Courtney (1992). These authors compared FR responding of pigeons in transitions between different multiple-schedule components, in which one component was "favorable" (i.e., a relatively large reinforcer maintained responding) and a second was "unfavorable" (i.e., a smaller reinforcer maintained responding). Most relevant to the present discussion was the finding that pre-ratio pausing was of greatest duration in the favorable-tounfavorable transition (i.e., the least-efficient performance). At first glance, this finding seems inconsistent with a typical application of the high-p procedure (e.g., Ardoin et al., 1999), as well as the results of Pigeon Model 1, in that Ardoin et al. used the high-p procedure to enhance responding in a favorable-to-unfavorable transition. Although there are several procedural differences between Perone and Courtney and Pigeon Model 1 (e.g., free operant versus discrete trial), the most telling difference may be the delay to reinforcement in the different transitions. The longest delay to reinforcement, timed from stimulus onset, under the high FR in the pigeon model was $5 \mathrm{~s}$, whereas an FR 80 had to be completed in Perone and Courtney, which took much longer than $5 \mathrm{~s}$. The results of Perone and Courtney, therefore, may provide boundary conditions on the efficacy of the high-p procedure, in that it only may be effective, or at least be more effective, when the reinforcement delay correlated with the low-p request is relatively short. The study of compliance as a link between behavior analysis and social psychology has 
two components, method and theory. The potential utility for behavior analysts of considering methods used by social psychologists was exemplified in the present experiments. That is, both a consideration of the similarity between the high-p procedure and foot in the door, as well as the absence of a compliance technique in applied behavior analysis resembling door in the face, were the impetus for Pigeon Model 2. And, that compliance was increased in that model by a technique like door in the face has at least three implications. First, the generality of door in the face was extended in several ways (e.g., to a novel subject population). Second, as discussed above, door in the face may prove useful for applied behavior analysts in the treatment of behavior problems. And third, a technique for investigating behavior change in the experimental analysis of behavior was developed.

The many differences between the experimental methods used in behavior analysis and in social psychology may limit the exchange of interaction between the two fields. Socialpsychological research typically consists of a between-subject design, a relatively large number of subjects exposed to different conditions for a relatively short period of time, and inferential statistics to assess the results (e.g., Tesser, 1995). In contrast, behavior-analytic research typically consists of a within-subject design, a relatively small number of subjects exposed to the same conditions for a relatively long period of time, and, in general, an absence of inferential statistics (e.g., Pierce \& Epling, 1995). These differences in method have conceptual underpinnings: behavior analysts assert that their methods are necessary as they provide experimental control over behavior, as opposed to statistical control (cf. Sidman, 1960; Skinner, 1966). Thus, despite the present results mirroring those obtained in social psychology, behavior analysts likely will find utility in such "borrowed" social-psychological techniques only after those techniques have undergone the experimental scrutiny common in behavior-analytic research.

Notwithstanding the numerous differences in experimental methods between social psychology and behavior analysis, there probably is a greater discrepancy in theorizing between the two fields. To appreciate this discrepancy, consider the disparity between the goals of the two fields: in social psychology, it is the explanation of attitudes, behaviors, and cognitions (e.g., Tesser, 1995), whereas in behavior analysis it is the prediction and control of behavior (e.g., Skinner, 1966). This disparity illustrates what each field takes as both its own subject matter, as 
well as the appropriate subject matter of psychology overall. In the context of theorizing (i.e., how investigators in each field account for changes in their subject matter), social psychologists often rely on structures and processes that cannot be observed, whereas behavior analysts do not (cf. Skinner, 1950, 1966). The effects of foot in the door, for example, are interpreted in social psychology by an account based on self-image preservation (e.g., Freedman \& Fraser, 1966; cf. Bem, 1970), which is markedly different than the behavior-analytic interpretations of the high-p procedure discussed above.

It may be argued, however, that the appeal to memory in the context of the coupling principle (Killeen, 1994) departs from common behavior-analytic terminology (e.g., Lattal \& Abreu-Rodrigues, 1994). Given that memory is used in this context only as an intervening variable, however, as opposed to a hypothetical construct (MacCorquodale \& Meehl, 1948), seems to mitigate against such an argument. In addition, the effects purported to be explained by the coupling principle (i.e., a description of how the delay-of-reinforcement gradient is obtained) may be interpreted without the postulation of memory (e.g., Doughty \& Lattal, in press).

What then are the consequences of positing compliance as a link between behavior analysis and social psychology given this disparity in theorizing between the two fields? Behavior analysts seem to have taken two general approaches when investigating a topic typically addressed by "cognitive" theorizing. The first dismisses that theorizing entirely, replacing it with behavioral concepts and principles, and the second utilizes that theorizing as a starting point by defining cognitive terms behaviorally (cf. Killeen, 1994; Skinner, 1974). The latter approach is suggested here (also see below, Future compliance research) as the appropriate tactic for developing a comprehensive, behavior-analytic account of compliance due to the extensive, social-psychological literature on compliance and the explication of the principles underlying that compliance (e.g., Cialdini, 1984, 1995). In addition, there are instances in which social-psychological interpretations are consistent, at least somewhat, with behavioral concepts and principles.

To illustrate a case in which there is overlap between behavior-analytic and socialpsychological theorizing, consider both behavioral and perceptual contrast as they relate to door in the face. As noted above, a perceptual-contrast interpretation of door in the face is common in social psychology (e.g., Cialdini et al., 1975), and the findings from the second pigeon model 
may be interpreted in a way consistent with behavior-analytic research on behavioral contrast that also emphasizes the role of context (Williams, 1983, 2002). The differences between these two aforementioned interpretations are slight (e.g., the reliance on perception), and, thus, there may be other cases in which the consideration of social-psychological theorizing is useful for behavior analysts (e.g., Kraft \& Baum, 2001; cf. Guerin, 1992; Lana, 1994).

Different accounts of compliance change. The inadequacy of a behavioral-momentum account of the high-p procedure was discussed above, and consistent with other claims (e.g., Houlihan \& Brandon, 1996), it was suggested that an alternative framework for the high-p procedure seems necessary despite the utility of momentum theory for its creation and development. There are two general reasons for adopting a different framework. The first, that momentum theory is used differently across basic and applied behavior analysis, was discussed in detail in the literature review, and the second, that momentum theory has difficulty describing the current data, is explored further here.

According to a behavioral-momentum account, a high-p sequence is effective as it increases both the velocity (rate) and mass (resistance to disruption) of the response class compliance such that it persists when confronted with disruption (low-p request). At least two results from the present experiments seem inconsistent with such an account, given that the present methods model the high-p procedure. First, this account does not seem to predict the effects of the response-independent food deliveries in Pigeon Model 1. That is, it is unclear how the momentum of key pecking is enhanced by delivering reinforcers both independently of key pecking and in the absence of stimuli correlated with that pecking (but see Nevin, 1996). Second, if the function of the high-p sequence is to enhance the response class of compliance, then any member of that class ought to be made resistant to disruption. Therefore, if schedule completion is a component of compliance, then such a sequence ought to improve DRL-schedule responding rather than worsen it, as was observed in Experiment 3. Finally, the findings from Experiment 2 may not be inconsistent with a behavioral-momentum account of the high-p procedure, but it is unclear what the predictions of that theory are in such a situation.

An interpretation based on Killeen's (1994) reinforcement principles was offered as a means of interpreting the effects of the high-p procedure, by positing that a high-p sequence induces activity or arousal. The form of that activity then is dictated by current environmental 
conditions, as described by the coupling principle. To illustrate the value of this interpretation, consider the results obtained across experiments in which the reinforcement schedule in effect following the sequence of food deliveries was an FR, VI, or DRL. Based on coupling, the target response (i.e., key peck) dominates under an FR schedule due to its multiple occurrences just prior to food delivery, whereas both the key peck and other responses (e.g., circling) are likely to be selected under a VI schedule. And finally, inefficient DRL responding is predicted, at least with DRL criteria as high as in Experiment 3, due to the fact that only a single peck is most proximal with food delivery and is disproportionately affected at the expense of the entire "wait time." Thus, when responding is elevated by the high-p sequence, key pecking specifically is enhanced under both the FR and DRL schedule, increasing schedule completion in the former case and decreasing it in the latter. Under the VI schedule, however, key pecking is not enhanced reliably as it, in some sense, competes with other responses.

The above interpretation also describes previous research on the high-p procedure, and, as such, supports the assertion that there are functional similarities between the present experiments and cases of human compliance change. Mace et al. (1988) reported greater compliance with low-p requests when such a request followed a high-p sequence by $5 \mathrm{~s}$ as opposed to $20 \mathrm{~s}$, and this finding is consistent with the notion that the activity generated by the high-p sequence declines with time. In addition, Mace (1996) cited unpublished research demonstrating a positive relation between compliance with low-p requests and the number of preceding high-p requests, and this finding is consistent with the notion that a greater reinforcement rate generates greater activity. Also according to the present interpretation, a highp sequence consisting of either response-dependent or -independent reinforcers ought to increase subsequent responding similarly, and this result was obtained both in the present experiments and in previous work with humans (Kennedy et al., 1995; but see Mace et al., 1988).

Given that this interpretation describing the effects of the high-p procedure in terms of Killeen's (1994) reinforcement principles is valid, the next issue was whether a similar description (see Literature Review) also accounted for the effects of the second pigeon model. The goal of Experiment 1 was to address this issue further; however, the results of that experiment were inconclusive. With one of the three pigeons, two "mirror-image" sequences (i.e., FR 1-FR 1-Ext and Ext-Ext-FR 1) were functionally equivalent in their effects on 
subsequent responding. For the other two pigeons, however, there either was a disruption in stimulus control or the absence of a replicable effect with the different sequences. Thus, the validity of a response-activation interpretation for the effects observed in Pigeon Model 2 must await further examination.

As already noted, the present, response-activation interpretation describes the effects of response-independent stimulus delivery (e.g., Kennedy et al., 1995), and as this manipulation is somewhat similar to task interspersal (see above; e.g., Neef et al., 1980), the effects of the latter may be interpreted in similar terms. That is, the presence of the already-learned items increases the reinforcement rate correlated with the worksheet such that responding is elevated, relative to when those items are omitted. And finally, given the similarity between the high-p procedure and foot in the door, applying the present interpretation to this latter technique seems plausible. Thus, responding occasioned by the large request may be made more probable when preceded by compliance with a small request by the arousing effects of reinforcement provided by that initial compliance episode. This latter description is supported further by the fact that there are more similarities between the high-p procedure and foot in the door than those listed above (see Burger, 1999, for a recent review on foot in the door). There is, however, substantially more research on foot in the door than the high-p procedure, and, consequently, it is unknown how functionally similar these two techniques actually are. Extending the present, response-activation interpretation to door in the face, however, is difficult as the results of Experiment 1 were inconclusive. And although a single interpretation was offered for the other compliance techniques discussed here, it may be that an alternative interpretation of Pigeon Model 2, and door in the face, is necessary (e.g., one based on behavioral contrast).

Concerns surrounding animal compliance. There are two general concerns that remain surrounding the notion of animal compliance, and the first follows from the above discussion on the relation between the present research and social-psychological work on compliance. Specifically, this first concern is the acknowledgement that only a portion of the variables controlling compliant behavior may be investigated with animals due to the potent influence of social factors on such behavior. This limitation is acknowledged here, however, it also is asserted that the present research yields information on the role of other important, nonsocial factors controlling compliant behavior (e.g., rate of reinforcement and the scheduling of such 
reinforcers).

The second concern is whether the functional response class of compliance was defined adequately in the experiments presented above. That is, it may be suggested that the probability of compliance per se was not altered in the present experiments but rather only the probability of pecking was. To illustrate this latter argument, consider the results of Pigeon Model 1 and Experiment 3. It may be argued that the food-delivery sequences only increased the probability of pecking such that schedule completion, or compliance as defined above, either increased (Pigeon Model 1) or decreased (Experiment 3). If this reasoning is accurate, then the conclusions raised above remain tenuous; consequently, further research assessing the validity of the above claims thus is necessary. One means of assessing which of the above arguments is accurate would involve the correlation of different response topographies with each of two requests, for example, investigating with pigeons how the reinforcement provided for key pecking affects subsequent treadle pressing under schedules identical to those utilized here.

Future compliance research. There were many differences between the baseline and test conditions of the present experiments. These differences include, in Pigeon Model 1 for example, the following: total number of trials, total number of trial types (i.e., a particular schedule), proportion of one trial type to another, total session time, and time between stimulus presentations. Although each of these changes ought to be studied further, the role of two factors probably are responsible for the present results, either alone or in conjunction with each other, overall rate of reinforcer delivery and the sequencing of those deliveries (cf. Mace et al., 1988). Thus, subsequent research ought to assess the relative impact of these latter two variables while controlling the other factors.

Potentially the next crucial step in elaborating on these animal models of compliance is to explore their connection to basic-behavior-analytic research with humans on verbal governance (see Shimoff \& Catania, 1998 for a review). This step is crucial as some investigators (e.g., Schmitt, 1998) have discussed the relation between this research and social-psychological work. To illustrate one possible link between these two aforementioned research areas and the present animal models, consider a variable affecting compliance reliably in social-psychological work, “authority" (Cialdini, 1984). That is, compliance generally is higher when a request is made by an individual that is an "expert" on a topic related to that request. A medical request, for 
example, is more likely to occasion compliance if a medical doctor presents the request than if someone without such training does. And this enhanced compliance may be due, in part, to a history of reinforcement for responding in accord with those instructions. This notion is related to, and entirely consistent with, behavior-analytic research wherein the rule following of humans is dictated by the accuracy of those rules (i.e., whether the responses occasioned by those rules lead to reinforcing, rather than punishing, consequences; e.g., Galizio, 1979). Thus, related to the present models, the issue is whether the above findings may be modeled with pigeons, for example, whether the accuracy of rules is analogous to conditions wherein the pecking of pigeons is reinforced probabilistically in the presence of distinct key-light colors.

Summary. It has been asserted repeatedly that research in the experimental analysis of behavior is important for many reasons, including its potential to impact the human condition (e.g., Skinner, 1953). Despite the repetition of this claim, there is a disconnection between the experimental analysis of behavior and applied behavior analysis (cf. Mace, 1994), and between behavior analysis and social psychology (cf. Guerin, 1992; Lana, 1994). One technique that integrates basic research with it application is the development of animal models (e.g., Lattal \& Doepke, 2001), and although animal models of compliance in particular have been discussed by applied researchers (Mace et al., 1997), they have not been forthcoming. The present experiments were designed to create such animal models and to investigate the behavioral variables operating in those models. It was concluded that at least two interpretations deserve further attention in the description of these controlling variables, one based on Killeen's (1994) principles of reinforcement and the other based on behavioral contrast (e.g., Williams, 1983, 2002). At the very least, the present results demonstrate the utility of a stronger link between basic and applied behavior analysts, and social psychologists, for a greater understanding of the environment-behavior relations subsumed by the label compliance. 


\section{References}

Amsel, A. (1994). Precis of frustration theory: An analysis of dispositional learning and memory. Psychonomic Bulletin \& Review, 1(3), 280-296.

Amsel, A., \& Roussel, J. (1952). Motivational properties of frustration: I. Effect on a running response of the addition of frustration to the motivational complex. Journal of Experimental Psychology, 43, 363-368.

Anderson, C. M., \& McMillan, K. (2001). Parental use of escape extinction and differential reinforcement to treat food selectivity. Journal of Applied Behavior Analysis, 34, 511 515.

Ardoin, S. P., Martens, B. K., \& Wolfe, L. A. (1999). Using high-probability instruction sequences with fading to increase student compliance during transitions. Journal of Applied Behavior Analysis, 32, 339-351.

Azrin, N. H., Hutchinson, R. R., \& Hake, D. F. (1966). Extinction-induced aggression. Journal of the Experimental Analysis of Behavior, 9, 191-204.

Bell, M. C. (1999). Pavlovian contingencies and resistance to change in a multiple schedule. Journal of the Experimental Analysis of Behavior, 72, 81-96.

Bem, D. J. (1970). Self-perception theory. In L. Berkowitz (Ed.), Advances in experimental social psychology, Vol. 6, (pp. 1-62). New York, NY: Academic Press.

Bizo, L. A., \& White, G. K. (1994). Pacemaker rate in the behavioral theory of timing. Journal of Experimental Psychology: Animal Behavior Processes, 20(3), 308-321.

Brown, P. L., \& Jenkins, H. M. (1968). Auto-shaping of the pigeon's key-peck. Journal of the Experimental Analysis of Behavior, 11, 1-8.

Burger, J. M. (1999). The foot-in-the-door compliance procedure. Personality and Social Psychology Review, 3(4), 303-325.

Catania, A. C., \& Reynolds, G. S. (1968). A quantitative analysis of the responding maintained by interval schedules of reinforcement. Journal of the Experimental Analysis of Behavior, 11, 327-383.

Cialdini, R. B. (1984). Influence: How and why people agree to things. New York: William Morrow \& Company, Inc. 
Cialdini, R. B. (1995). Principles and techniques of social influence. In A. Tesser (Ed.), Advanced social psychology, (pp. 257-281). Boston, MA: McGraw-Hill.

Cialdini, R. B., Vincent, J. E., Lewis, S. K., Catalan, J., Wheeler, D., \& Darby, B. L. (1975). Reciprocal concessions procedure for inducing compliance: The door-in-the-face technique. Journal of Personality and Social Psychology, 31(2), 206-215.

Cohen, M., \& Davis, N. (1981). Medication errors: Causes and prevention. Philadelphia, PA: G. F. Stickley Co.

Crespi, L. P. (1942). Quantitative variation in incentive and performance in the white rat. The American Journal of Psychology, 40, 467-517.

Davis, C. A., \& Reichle, J. (1996). Variant and invariant high-probability requests: Increasing appropriate behaviors in children with emotional-behavioral disorders. Journal of Applied Behavior Analysis, 29, 471-482.

Dinsmoor, J. A., Lee, D. M., \& Brown, M. M. (1986). Escape from serial stimuli leading to food. Journal of the Experimental Analysis of Behavior, 46, 259-279.

Doughty, A. H. \& Lattal, K. A. (in press). Response persistence under variable-time schedules following immediate and unsignalled delayed reinforcement. Quarterly Journal of Experimental Psychology: Comparative and Physiological Psychology.

Doughty, A. H., \& Richards, J. B. (2002). Effects of reinforcer magnitude on responding under differential-reinforcement-of-low-rate schedules of rats and pigeons. Journal of the Experimental Analysis of Behavior, 78, 17-30.

Flaherty, C. F. (1996). Incentive Relativity. Cambridge: Cambridge University Press.

Fleshler, M., \& Hoffman, H. S. (1962). A progression for generating variable-interval schedules. Journal of the Experimental Analysis of Behavior, 5, 529-530.

Freedman, J. L., \& Fraser, S. C. (1966). Compliance without pressure: The foot-in-the-door technique. The Journal of Personality and Social Psychology, 4, 237-248.

Freeman, K. A., \& Piazza, C. C. (1998). Combining stimulus fading, reinforcement, and extinction to treat food refusal. Journal of Applied Behavior Analysis, 31, 691-694.

Galizio, M. (1979). Contingency-shaped and rule-governed behavior: Instructional control of human loss avoidance. Journal of the Experimental Analysis of Behavior, 31, 53-70. 
Grace, R. C., Schwendiman, J. W., \& Nevin, J. A. (1998). Effects of unsignaled delay of reinforcement on preference and resistance to change. Journal of the Experimental Analysis of Behavior, 69, 247-261.

Guerin, B. (1992). Behavior analysis and social psychology: A review of Lana's Assumptions of Social Psychology. Journal of the Experimental Analysis of Behavior, 58, 589-604.

Hake, D. F. (1982). The basic-applied continuum and the possible evolution of human operant social and verbal behavior. The Behavior Analyst, 5, 21-28.

Hineline, P. N. (1978). Warmup in avoidance as a function of time since prior training. Journal of the Experimental Analysis of Behavior, 29, 87-103.

Hoffman, H. S., Fleshler, M., \& Chorny, H. (1961). Discriminated bar-press avoidance. Journal of the Experimental Analysis of Behavior, 4, 309-316.

Houlihan, D., \& Brandon, P. K. (1996). Compliant in a moment: A commentary on Nevin. Journal of Applied Behavior Analysis, 29, 549-555.

Kennedy, C. H., Itkonen, T., \& Lindquist, K. (1995). Comparing interspersed requests and social comments as antecedents for increasing student compliance. Journal of Applied Behavior Analysis, 28, 97-98.

Killeen, P. R. (1979). Arousal: Its genesis, modulation, and extinction. In M. D. Zeiler \& P. Harzem (Eds.), Advances in analysis of behavior: Vol. 1. Reinforcement and the Organization of behavior (pp. 31-78). Chichester, England: Wiley.

Killeen, P. R. (1982). Incentive theory. In D. J. Bernstein (Ed.), Nebraska symposium on motivation, 1981: Response structure and organization. University of Nebraska Press.

Killeen, P. R. (1994). Mathematical principles of reinforcement. Behavioral and Brain Sciences, 17, 105-172 (with commentaries).

Killeen, P. R. (1998). The first principle of reinforcement. In C. D. L. Wynne \& J. E. R. Staddon (Eds.), Models of action: Mechanisms for adaptive behavior, (pp. 127-156). Mahwah, NJ: Lawrence Erlbaum Associates.

Killeen, P. R. (2000). A passel of metaphors: "Some old, some new, some borrowed..." Behavioral and Brain Sciences, 23, 102-103.

Killeen, P. R., \& Bizo, L. A. (1998). The mechanics of reinforcement. Psychonomic Bulletin \& Review, 5(2), 221-238. 
Killeen, P. R., Hanson, S. J., \& Osborne, S. R. (1978). Arousal: Its genesis and manifestation as response rate. Psychological Review, 85, 571-581.

Kraft, J. R., \& Baum, W. M. (2001). Group choice: The ideal free distribution of human social behavior. Journal of the Experimental Analysis of Behavior, 76, 21-42.

Lana, R. E. (1994). Social history and the behavioral repertoire. Journal of the Experimental Analysis of Behavior, 62, 315-322.

Lattal, K. A. (2001). The human side of animal behavior. The Behavior Analyst, 24, 147-161.

Lattal, K. A., \& Abreu-Rodrigues, J. (1994). Memories and functional response units. Behavioral and Brain Sciences, 17 , 143-144.

Lattal, K. A., \& Doepke, K. J. (2001). Correspondence as conditional stimulus control: Insights from experiments with pigeons. Journal of Applied Behavior Analysis, 34, 127-144.

Lewis, P. \& Dougherty, D. M. (1992). Pigeon performance on a variable-interval omission schedule at different levels of food deprivation. Behavioural Processes, 27, 27-36.

MacCorquodale, K. \& Meehl, P. E. (1948). On a distinction between hypothetical constructs and intervening variables. Psychological Review, 55, 95-107.

Mace, C. F. (1994). Basic research needed for stimulating the development of behavioral technologies. Journal of the Experimental Analysis of Behavior, 61, 529-550.

Mace, F. C. (1996). In pursuit of general behavioral relations. Journal of Applied Behavior Analysis, 29, 557-563.

Mace, C. F. (2000). Clinical applications of behavioral momentum. Behavioral and Brain Sciences, 23, 105-106.

Mace, F. C., Hock, M. L., Lalli, J. S., West, B. J., Belfiore, P., Pinter, E., \& Brown, D. K. (1988). Behavioral momentum in the treatment of noncompliance. Journal of Applied Behavior Analysis, 21, 123-141.

Mace, F. C., Mauro, B. C., Boyajian, A. E., \& Eckert, T. L. (1997). Effects of reinforcer quality on behavioral momentum: Coordinated applied and basic research. Journal of Applied Behavior Analysis, 30, 1-20.

Malone, J. C., Jr. (1976). Local contrast and Pavlovian induction. Journal of the Experimental Analysis of Behavior, 26, 425-440. 
McComas, J. J., Wacker, D. P., \& Cooper, L. J. (1998). Increasing compliance with medical procedures: Application of the high-probability request procedure to a toddler. Journal of Applied Behavior Analysis, 31, 287-290.

McGill, P. (1999). Establishing operations: Implications for the assessment, treatment, and prevention of problem behavior. Journal of Applied Behavior Analysis, 32, 393-418.

MED Associates, Inc., \& Tatham, T. A. (1991). MED-PC Medstate notation. East Fairfield, NH: MED Associates, Inc.

Michael, J. (1982). Distinguishing between discriminative and motivational functions of stimuli. Journal of the Experimental Analysis of Behavior, 37, 149-155.

Michael, J. (1993). Establishing operations. The Behavior Analyst, 16, 191-206.

Michael, J. (2000). Implications and refinements of the establishing operation concept. Journal of Applied Behavior Analysis, 33, 401-410.

Neef, N. A., Iwata, B. A., \& Page, T. J. (1980). The effects of interspersal training versus highdensity reinforcement on spelling acquisition and retention. Journal of Applied Behavior Analysis, 13, 153-158.

Nevin, J. A. (1974). Response strength in multiple schedules. Journal of the Experimental Analysis of Behavior, 21, 389-408.

Nevin, J. A. (1992). An integrative model for the study of behavioral momentum. Journal of the Experimental Analysis of Behavior, 57, 301-316.

Nevin, J. A. (1996). The momentum of compliance. Journal of Applied Behavior Analysis, 29, 535-547.

Nevin, J. A. (1994). Extension to multiple schedules: Some surprising (and accurate) predictions. Behavioral and Brain Sciences, 17 , 145-146.

Nevin, J. A., \& Grace, R. C. (2000). Behavioral momentum and the law of effect. Behavioral and Brain Sciences, 23, 73-130 (with commentaries).

Nevin, J. A., Mandell, C., \& Atak, J. R. (1983). The analysis of behavioral momentum. Journal of the Experimental Analysis of Behavior, 39, 49-59.

Perone, M., \& Courtney, K. (1992). Fixed-ratio pausing: Joint effects of past reinforcer magnitude and stimuli correlated with upcoming magnitude. Journal of the Experimental Analysis of Behavior, 57, 33-46. 
Pierce, W. D., \& Epling, W. F. (1995). Behavior analysis and learning. Englewood Cliffs, NJ: Prentice Hall.

Pliner, P., Hart, H., Kohl, J., \& Saari, D. (1974). Compliance without pressure: Some further data on the foot-in-the-door technique. Journal of Experimental Social Psychology, 10, $17-22$.

Rortvedt, A. K., \& Miltenberger, R. G. (1994). Analysis of a high-probability instructional sequence and time-out in the treatment of child noncompliance. Journal of Applied Behavior Analysis, 27, 327-330.

Schmitt, D. R. (1998). Effects of consequences of advice on patterns of rule control and rule choice. Journal of the Experimental Analysis of Behavior, 70, 1-21.

Shimoff, E., \& Catania, A. C. (1998). The verbal governance of behavior. In K. A. Lattal \& M. Perone (Eds.), Handbook of research methods in human operant behavior, (pp. 371-404). New York: Plenum.

Sidman, M. (1960). Tactics of scientific research. Boston, MS: Authors Cooperative, Inc., Publishers.

Skinner, B. F. (1938). The behavior of organisms: An experimental analysis. New York: Appleton-Century-Crofts.

Skinner, B. F. (1950). Are theories of learning necessary? Psychological Review, 57, 193-216.

Skinner, B. F. (1953). Science and human behavior. New York: Macmillan.

Skinner, B. F. (1957). Verbal behavior. New York: Appleton-Century-Crofts.

Skinner, B. F. (1966). What is the experimental analysis of behavior? Journal of the Experimental Analysis of Behavior, 9, 213-218.

Skinner, B. F. (1971). Beyond freedom and dignity. New York: Alfred A. Knopf.

Skinner, B. F. (1974). About behaviorism. New York: Alfred A. Knopf.

Smith, R. G., \& Iwata, B. A. (1997). Antecedent influences on behavior disorders. Journal of Applied Behavior Analysis, 30, 343-375.

Staddon, J. E. R. (1965). Some properties of spaced responding in pigeons. Journal of the Experimental Analysis of Behavior, 8, 19-27.

Tesser, A. (1995). Advanced social psychology, (pp. 257-281). Boston, MA: McGraw-Hill. 
Williams, B. A. (1981). The following schedule of reinforcement as a fundamental determinant of steady state contrast in multiple schedules. Journal of the Experimental Analysis of Behavior, 35, 293-310.

Williams, B. A. (1983). Another look at contrast in multiple schedules. Journal of the Experimental Analysis of Behavior, 39, 345-384.

Williams, B. A. (1997). Varieties of contrast: A review of Incentive Relativity by Charles F. Flaherty. Journal of the Experimental Analysis of Behavior, 68, 133-141.

Williams, B. A. (2002). Behavioral contrast redux. Animal Learning and Behavior, 30(1), 120. 